\title{
Key structural parameters affecting earthquake ground motion in 2D and 3D sedimentary structures
}

\author{
Peter Moczo $^{1,2} \cdot$ Jozef Kristek $^{1,2} \cdot$ Pierre-Yves Bard $^{3}$ • \\ Svetlana Stripajová ${ }^{1}$. Fabrice Hollender ${ }^{4}$ - Zuzana Chovanováa ${ }^{2}$ \\ Miriam Kristeková ${ }^{1,2} \cdot$ Deborah Sicilia $^{5}$
}

Received: 19 September 2017/Accepted: 2 March 2018/Published online: 12 March 2018

(C) The Author(s) 2018. This article is an open access publication

\begin{abstract}
Alluvial valleys generate strong effects on earthquake ground motion (EGM). These effects are rarely accounted for even in site-specific studies because of (a) the cost of the required geophysical surveys to constrain the site model, (b) lack of data for empirical prediction, and (c) poor knowledge of the key controlling parameters. We performed 3D, 2D and 1D simulations for six typical sedimentary valleys of various width and depth, and for a variety of modifications of these 6 "nominal models" to investigate sensitivity of EGM characteristics to impedance contrast, attenuation, velocity gradient and geometry. We calculated amplification factors, and 2D/1D and 3D/2D aggravation factors for 10 EGM characteristics, using a representative set of recorded accelerograms to account for input motion variability. The largest values of the amplification and aggravation factors are found for the Arias intensity and cumulative absolute velocity, the lowest for the rootmean-square acceleration. The aggravation factors are largest for the vertical component. For each model, at least one EGM characteristic exhibits a significant 2D/1D aggravation factor, while all EGM characteristics exhibit significant 2D/1D aggravation factor on the vertical component. For all investigated sites, there is always an area in the valley for which 1D estimates are not sufficient. 2D estimates are insufficient at several sites. The key
\end{abstract}

Electronic supplementary material The online version of this article (https://doi.org/10.1007/s10518-0180345-5) contains supplementary material, which is available to authorized users.

Peter Moczo

moczo@fmph.uniba.sk

1 Faculty of Mathematics, Physics and Informatics, Comenius University Bratislava, Mlynska dolina F1, 84248 Bratislava, Slovakia

2 Earth Science Institute, Slovak Academy of Sciences, Dubravska cesta 9, 84528 Bratislava, Slovakia

3 CNRS/IRD/IFSTTAR, ISTerre, Univ. Grenoble Alpes, CS 40700, 38058 Grenoble Cedex 9, France

4 French Alternative Energies and Atomic Energy Commission (CEA), Saint-Paul-lez-Durance, France

5 CEIDRE-TEGG, Electricite de France (EdF), Aix-en-Provence, France 
structural parameters are the shape ratio and overall geometry of the sediment-bedrock interface, impedance contrast at the sediment-bedrock interface, and attenuation in sediments. The amplification factors may largely exceed the values that are usually considered in GMPEs between soft soils and rock sites.

Keywords Site acceleration · Earthquake ground motion · Amplification factor · Aggravation factor · Numerical modelling

\section{Introduction}

Soft sediments have been known for a long time now as modifying (most often amplifying) earthquake ground motion and increasing damage: this resulted in their accounting in hazard assessment studies and building codes through simplified site characterization, coupled with site-dependent spectral shapes and levels of motions. All the site proxies used for such purposes implicitly refer to the local, 1D, structure of the site, and do not take into account the possibility of variations of the underground structure around the considered site, and the potentially associated effects on the intensity and characteristics of ground motion.

Meanwhile, a large number of cities or critical facilities are located in alluvial valleys or sedimentary basins with pronounced 2D or 3D underground geometry. Many investigations of different kinds have thus been carried out over the last 5 decades about the seismic response of such non-1D soil structures. Some addressed mainly the physics of wave propagation in generic valleys or basins, some were dedicated to case studies for specific sites either hit by strong events (such as Caracas, Mexico City, Los Angeles or SeattleVancouver basins, Kobé-Osaka areas, Kanto plain, for example) or being the focus of dense instrumentation (Mygdonian basin in Greece, alpine valleys such as the Grenoble and Martigny areas in Western European Alps); some other had more applied objectives, from the benchmarking of numerical codes on canonical cases or real sites (see, e.g., Moczo and Irikura 1999; Day et al. 2003; Chaljub et al. 2010; Maufroy et al. 2015, 2016, 2017), to the attempt to quantify the associated amplification effects (e.g., SISMOVALP project, Lacave and Lemeille 2006; Barnaba et al. 2010).

Summarizing the results of all these studies is much beyond the scope of the present article. In short, the lateral variations of thickness in alluvial valleys or basins have been shown to generate peculiar wave propagation phenomena (diffraction of surface waves, possible focusing of body waves, vertical and lateral reverberations) leading to increased wave trapping and interferences, and significant differences (increased duration, mostly overamplification, sometimes deamplification) with respect to the case of horizontally stratified layers ("1D soil columns"). Despite their qualitative prediction by theory for several decades, and their actual observation in real recordings or damage distribution (e.g., in Kobe in 1995), such effects are only very rarely accounted for even in site-specific studies, because of (a) the cost of the required geophysical surveys to constrain geomechanical parameters of the underground structure not only underneath but also around the target site, (b) the insufficient number of well-documented observations that prevents any statistical treatment for a purely empirical prediction, and (c) the lack of comprehensive enough parameter study that would allow to identify the key controlling parameters and to quantify their effects.

The last issue has been addressed in a number of recent works, one of the last ones being the European project NERA (see deliverable D11.5 at http://www.orfeus-eu.org/ 
organization/projects/NERA/Deliverables/), as partly illustrated by Riga et al. (2016): following the initial paper by Chávez-García and Faccioli (2000), it has become usual to characterize these geometrical effects through an "aggravation factor" which quantifies the ratio between 2D (or 3D) and 1D ground motion amplification at a given site (see also Chávez-García 2007). This was done, e.g., by Makra et al. (2001, 2005) for the Euroseistest site (Mygdonian basin, Greece), by Paolucci and Morstabilini (2006) for a family of hypothetical basin edges (walls or wedges), by Kumar and Narayan (2008), Narayan and Richharia (2008), Hasal and Iyisan (2012), Gelagoti et al. (2012) and Vessia and Russo (2013) for hypothetical basins in the non-linear and linear equivalent cases. Such engineering-oriented studies use most often the aggravation factor on the response-spectra amplification factor, and generally end up with values of aggravation factor below 2except for Makra et al. (2001, 2005) and Hasal and Iyisan (2012) for whom aggravation factor reach values up to 4 in specific cases. However, despite the significance of the associated computational efforts, there is not yet a wide consensus on the amount of such "over-amplification" (which may indeed sometimes consist in "under-amplification, especially close to the edges, see, e.g., Riga et al. 2016), and the task is so huge and the way is long before such coefficients can be accepted and used in building codes.

The present study is another contribution to this general issue, having in mind, however, a specific kind of application, related to critical facilities such as nuclear power plants, for which in principle, some significant budget should be available to perform the required geophysical and geotechnical surveys, to better know the underground structure. The study was performed within the framework of the CASHIMA and SIGMA research projects related with the estimation of site-specific hazard for nuclear facilities, and intended to bring answers to two main questions:

a. What could be the amount of actual amplification for realistic situations, especially as it may exceed by far what is predicted by GMPEs based on simple, 1D site proxies?

b. In which case is the aggravation factor significant, or in other terms, when $2 \mathrm{D}$ or $3 \mathrm{D}$ site response studies should be required?

As there are not yet enough recordings from very well documented sites with enough "geomechanical" metadata, it is still impossible to provide empirical answers to those questions. Thus the problem was addressed from a numerical viewpoint in the following way:

- Six realistic site geometries have been selected (including two sites with extensive validation against data-Euroseistest and Grenoble), for which 1D, 2D and sometimes 3D computations have been performed and systematically compared for a large number of receivers (5251 in total) located either within the valleys of basins, or on the bedrock edges.

- Several earthquake ground motion characteristics have been selected because of their engineering relevance for such a comparison: for each of them (scalar or vector) both the amplification levels (with respect to the reference) and the aggravation factors have been computed as detailed in the companion article by Kristek et al. (2018). The characteristic-to-characteristic have also been analysed to identify a limited set of quasi-independent characteristic to be analysed in more detail.

- In addition to the six "nominal models" with a given geometry and a given set of mechanical parameters (velocities, density, attenuation), sensitivity studies have been performed to investigate the sensitivity to impedance contrast, attenuation, velocity 
gradient and geometry), in view of identifying the key parameters to be known/ measured for a new site.

- A specific attention has been paid also to the rock sites located on each side of the valleys in order to assess the amount of variability of the rock ground motion due to the feedback from the valley or basin.

\section{Overview of sites and computations}

We perform extensive numerical simulations for two sets of structural models: the first set of "nominal" models corresponds to real sites representing a meaningful scatter of local surface sedimentary and bedrock conditions, whereas the second set consists of modifications to the nominal models for investigating sensitivity of several "EGM" (Earthquake Ground Motion) characteristics to important structural features. The set of nominal models consists of a few typical surface sedimentary structures: Site 1 (Mygdonian basin, near Thessaloniki, Greece)—a shallow sediment-filled basin, Site 2 (Grenoble valley, France)— a typical deep Alpine sediment-filled valley, Site 4-a small shallow sediment-filled valley, Site 5-a mid-size sediment-filled valley, Site 6-a relatively small shallow sediment-filled valley, and Site 7-a shallow relatively large sediment-filled valley. The set of modified models includes variations in velocity and attenuation in sediments, velocity in bedrock, geometry of the border slope, velocity and thickness of sediments, and 3D meander extension. Forward numerical simulations were performed in the linear domain with the finite-difference (FD) method (Moczo et al. 2014; Kristek and Moczo 2014; Chaljub et al. 2010, 2015). 3D simulations were performed for Sites 1, 2 and 6, assuming a vertical plane wave incidence, and also for several double-couple (DC) point sources located at different positions. 2D simulations were performed for selected 2D profiles in the 3D models (Sites 1 and 2) and also all other 2D nominal models and their variants (Sites 4-7) assuming the vertical plane wave incidence. 1D simulations have been performed with 1D models corresponding to all the selected receiver positions along all the $2 \mathrm{D}$ profiles.

\subsection{Sites}

\subsubsection{D models}

The Mygdonian basin (Site 1, shown in Fig. 1) is a relatively shallow sedimentary basin with gentle slopes and a complicated geometry of the sediment-bedrock interface, relatively low $V_{S}$ (S-wave speed) near the surface (Online Resource 2), large $V_{S}$ contrast between sediments and bedrock ranging from 3 to $18, V_{P} / V_{S}$ larger than 10 at the surface ( $V_{P}$ meaning the $\mathrm{P}$-wave speed). Extensive surface waves can be generated in the basin. There are 3 selected distinct 2D profiles for detail investigation.

The Grenoble valley (Site 2, shown in Fig. 2) is a typical, deep, Alpine sediment-filled valley and has a complicated geometry of the sediment-bedrock interface, relatively low $V_{S}$ near the surface, large $V_{S}$ contrast between sediments and bedrock ranging from 3.5 to 10 , and $V_{P} / V_{S}$ almost 7 at the surface (Online Resource 3). 2D or 3D low-frequency resonances might develop. There are 4 selected distinct $2 \mathrm{D}$ profiles. 


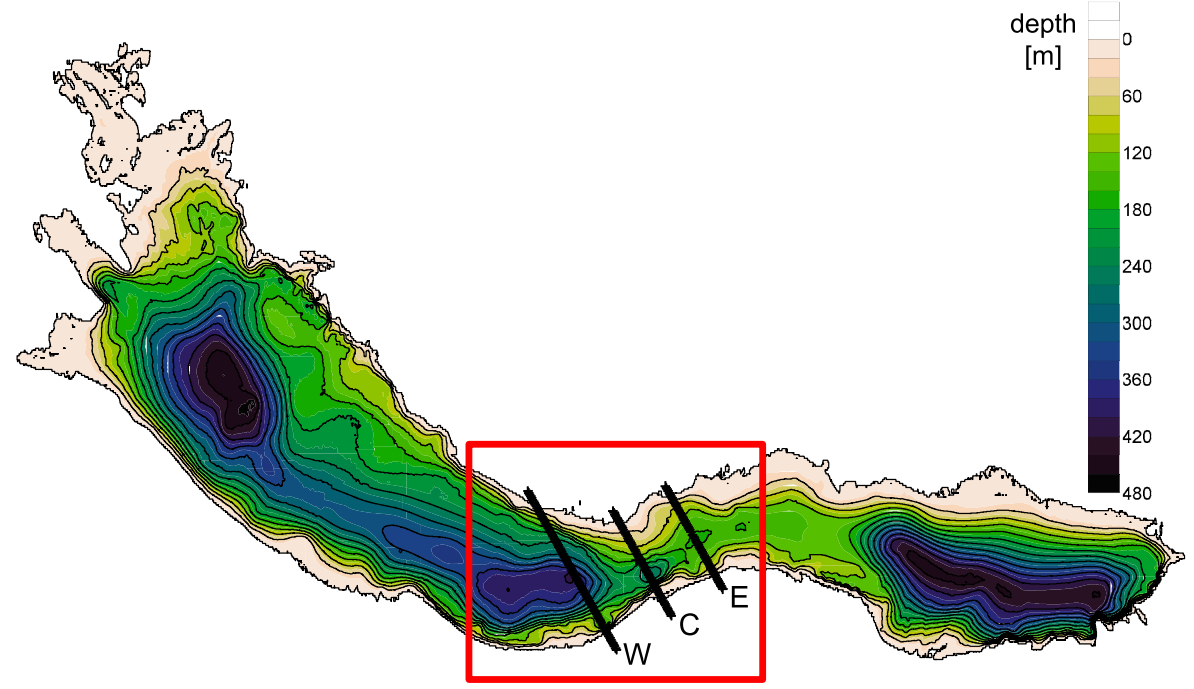

Fig. 1 Depth of the sediment-bedrock interface in the Mygdonian basin model (Site 1). The red frame shows the area of the computational model. Black lines indicate profiles of receivers positions $\mathrm{E}, \mathrm{C}$ and $\mathrm{W}$. Size of the whole depicted area is approx. $65 \times 48 \mathrm{~km}^{2}$

A meander-like model is a 3D extension of 2D models of Site 6 (the next section). The model is shown in Fig. 3. In the simulation we assumed an infinite extension by setting equality of the left-hand side and right-hand side boundaries for the depicted model.

\subsubsection{D models}

Site 4 is the smallest of the investigated sedimentary structures, consisting of a shallow valley (thickness $120 \mathrm{~m}$, width $920 \mathrm{~m}$ ) with velocity gradient in sediments (Online Resource 4) and local fundamental resonant frequencies above $2 \mathrm{~Hz}$. Site 5 is a mid-size, deep sediment-filled valley (thickness $581 \mathrm{~m}$, width $3.5 \mathrm{~km}$ ) with relatively strong velocity gradient in sediments (Online Resource 5), relatively large contrast at the sediment-bedrock interface and local fundamental resonant frequencies below $1 \mathrm{~Hz}$, the minimum being around $0.5 \mathrm{~Hz}$. Site 6 has an intermediate size (thickness $161 \mathrm{~m}$, width $2.2 \mathrm{~km}$ ), between sizes of sites 4 and 5, and presents a thin low-velocity layer at the surface and a large velocity contrast at the sediment-bedrock interface; the corresponding local fundamental resonant frequencies are around $1 \mathrm{~Hz}$. There are 2 alternative models: one with a thin, soft layer $\left(V_{S}=230 \mathrm{~m} / \mathrm{s}, 5 \mathrm{~m}\right.$ thickness) overlying homogeneous sediments with a $600 \mathrm{~m} / \mathrm{s}$ $\mathrm{S}$-wave velocity, one with the same top thin, soft layer, overlying sediments with a gradient in the P-and S-wave velocities (Online Resource 6). Site 7 is the relatively large, shallow valley (thickness $510 \mathrm{~m}$, width $6.2 \mathrm{~km}$ ) with three layers of sediments, two of them with strong gradients (Online Resource 7). There is a large velocity contrast at the sedimentbedrock interface. The fundamental resonant frequencies are below $1 \mathrm{~Hz}$, the minimum being approximately $0.5 \mathrm{~Hz}$.

Together with the 7 selected profiles in the Mygdonian basin and Grenoble valley we thus have 12 2D models shown in Fig. 4. Selected mechanical and geometrical parameters of all models are shown in Fig. 5. 

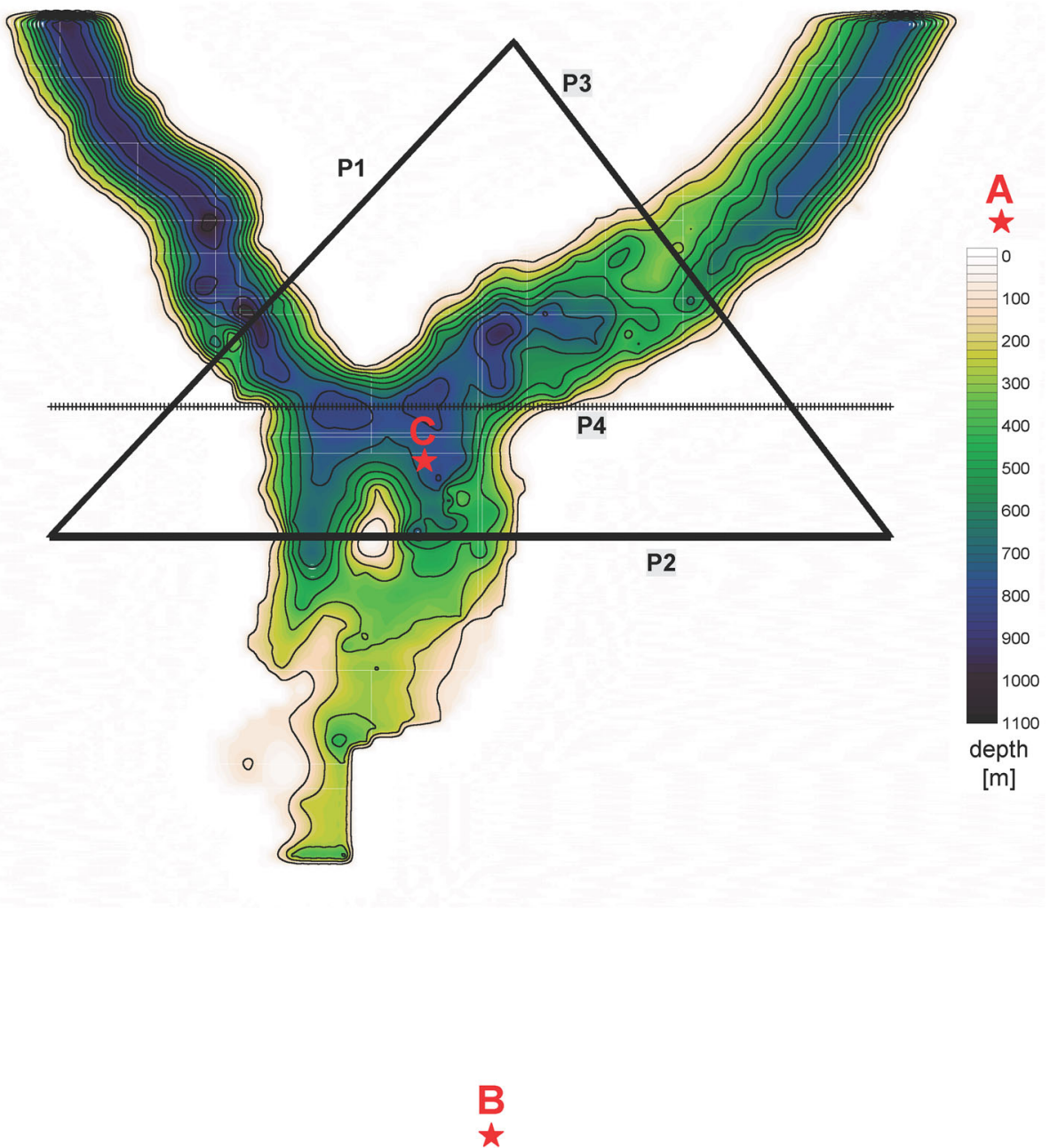

Fig. 2 Depth of the sediment-bedrock interface in the Grenoble valley model (Site 2). The red stars show $\mathrm{A}, \mathrm{B}$ and $\mathrm{C}$ positions of the DC point sources for 3D numerical simulations. Black lines indicate profiles of receiver positions $\mathrm{P} 1-\mathrm{P} 4$. Size of the whole depicted area is approx. $27 \times 30 \mathrm{~km}^{2}$

\subsection{Sensitivity studies}

A set of modifications of the nominal models was defined in order to analyse effects of a few carefully selected structural parameters on the EGM characteristics, in view of identifying the most robust results and those which are so sensitive that their estimation requires the prior measurement of a few controlling parameters.

- In the model of the Grenoble valley a high-velocity layer at the free surface was alternatively assumed, corresponding to the realistic situation where recent, fluviatile gravel layers overtop older, softer, lacustrine clayey deposits.

- Alternative attenuation parameters were also considered for the Grenoble valley models $\left(Q_{S}\right.$ derived from 1D nonlinear simulations to investigate the impact of larger 


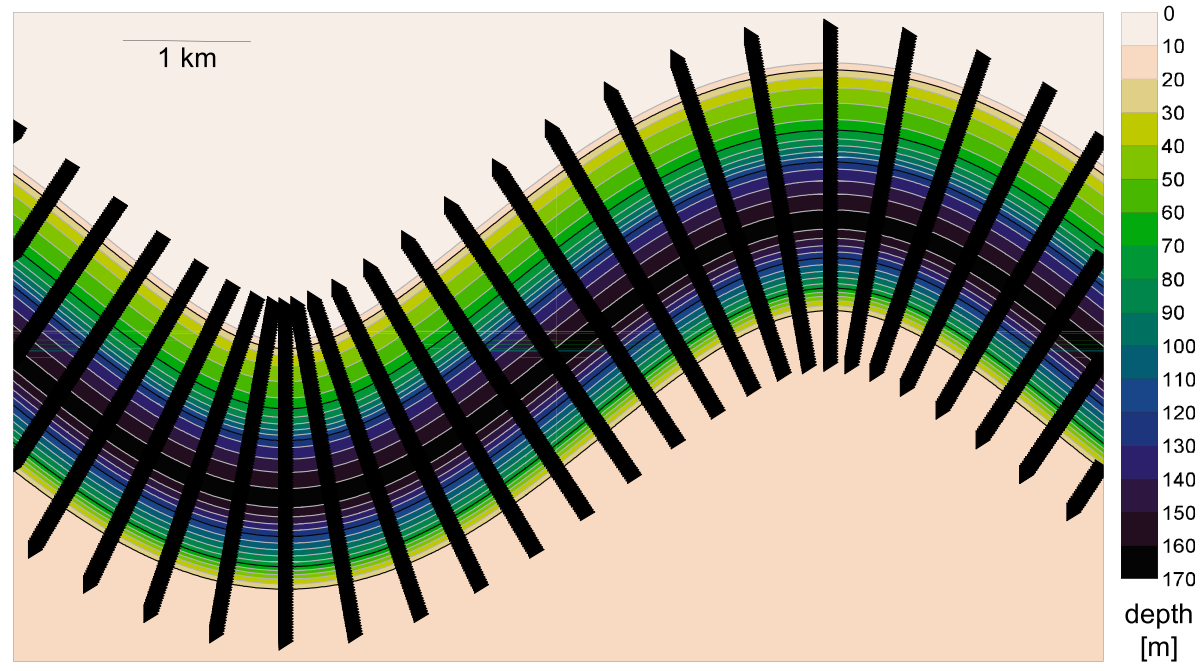

Fig. 3 Depth of the sediment-bedrock interface in the 3D meander extension of 2D models of Site 6. Grenoble valley model (Site 2). Black lines indicate profiles of receiver positions

attenuation throughout the very thick deposits on the 3D and 2D responses) and Sites 5-7 (different $Q_{S}-V_{S}$ scaling, from no attenuation at all to $Q_{S}=V_{S} / 20$ and $\left.Q_{S}=V_{S} / 40\right)$.

- The effect of the detail of valley edge geometry was investigated by considering alternative sloping angles for the sediment-bedrock interface for various $2 \mathrm{D}$ models: Grenoble profile P1, Sites 5 and 6.

- The impact of the sediment/bedrock impedance contrast was investigated by considering alternative bedrock velocities for models of Sites 5-7, and also by alternative velocities in sediments for site S6h.

- In two modifications of model S6h simultaneous variations in the velocity and thickness of sediments were considered: the velocity in the homogeneous sediments is increased by $40 \%$ in one modification and decreased by $40 \%$ in the other while the local sediment thickness is increased/decreased, respectively, in order to keep the local 1D fundamental resonant frequency unchanged. The sediment P-wave velocity is however kept unchanged, as they correspond to high Poisson ratio, water saturated sediments.

- Eventually, 3D meander extensions were considered for models S6h and S6g. Thus 3D and 2D models for Sites 1, 2 and 6 make it possible to quantify the differences between $2 \mathrm{D}$ and $3 \mathrm{D}$ site responses.

All the alternative models are indicated in Fig. 6.

\subsection{Numerical simulations and computations of ground motion characteristics}

For all specified models we computed a set of selected EGM characteristics based on methodology described in detail in the accompanying article by Kristek et al. (2018). In the first step, 3D, 2D and 1D FD simulations were performed for all 3D, 2D and 1D models, respectively, in order to obtain pseudoimpulse responses. Figure 6 shows an overview of 


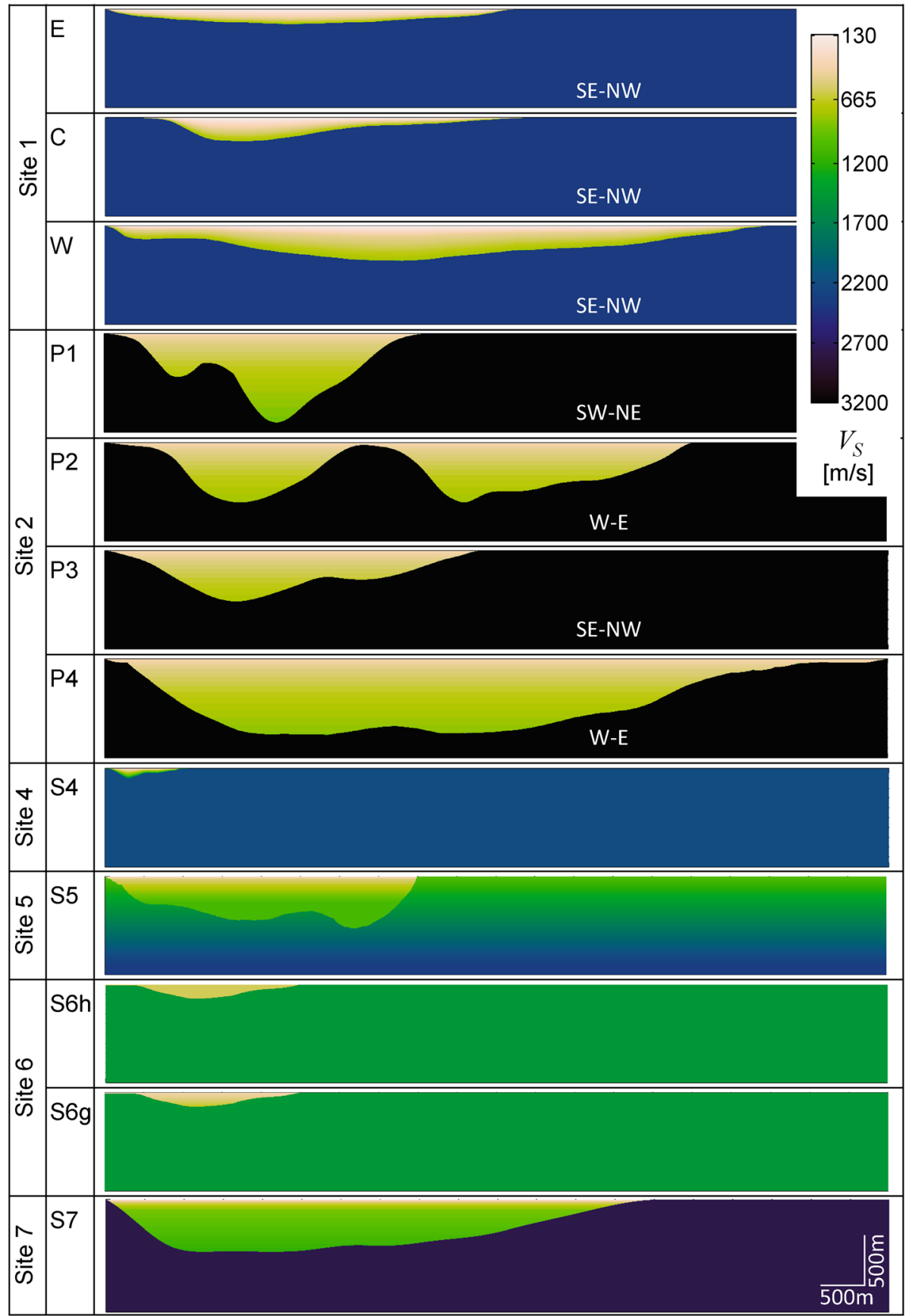

Fig. 4 Geometry of the sediment-bedrock interface and S-wave speed in the nominal-model profiles. The profiles are denoted by symbols in the left column. The horizontal-to-vertical scale is $1: 1$. The $S$-wave speed is shown using colour scale by Niccoli (2014). $N$ North, $S$ South, $W$ West, $E$ East 


\begin{tabular}{|c|c|c|c|c|c|c|c|c|c|c|}
\hline \multirow{2}{*}{ Site } & \multirow{2}{*}{ 这 } & $V_{S \text { min }}$ & $V_{S 30}$ & $\overline{V_{S}}$ & $W$ & $z_{\max }$ & $V_{S \mathrm{~b}}$ & $f_{00}$ & $z_{\max } / W$ & $V_{S \mathrm{~b}} / V_{S 30}$ \\
\hline & & {$[\mathrm{m} / \mathrm{s}]$} & {$[\mathrm{m} / \mathrm{s}]$} & {$[\mathrm{m} / \mathrm{s}]$} & {$[\mathrm{m}]$} & {$[\mathrm{m}]$} & {$[\mathrm{m} / \mathrm{s}]$} & {$[1 / \mathrm{s}]$} & & \\
\hline \multirow{3}{*}{ Site 1} & $\mathrm{E}$ & \multirow{3}{*}{130} & 180 & 400 & 4700 & 167 & \multirow{3}{*}{2600} & 0.7 & 0.04 & 14.5 \\
\hline & $\mathrm{C}$ & & 170 & 445 & 4900 & 266 & & 0.5 & 0.05 & 15.4 \\
\hline & W & & 175 & 520 & 7450 & 393 & & 0.5 & 0.05 & 15 \\
\hline \multirow{4}{*}{ Site 2} & P1 & \multirow{4}{*}{267} & \multirow{4}{*}{380} & 680 & 3580 & 993 & \multirow{4}{*}{3200} & 0.2 & 0.3 & \multirow{4}{*}{8.5} \\
\hline & $\mathrm{P} 2$ & & & 610 & 6590 & 670 & & 0.3 & 0.1 & \\
\hline & P3 & & & 590 & 4210 & 570 & & 0.3 & 0.1 & \\
\hline & $\mathrm{P} 4$ & & & 660 & 8750 & 844 & & 0.2 & 0.1 & \\
\hline Site 4 & S4 & 250 & 400 & 700 & 920 & 120 & 2200 & 2.2 & 0.2 & 5.5 \\
\hline Site 5 & S5 & 275 & 410 & 920 & 3500 & 581 & gradient & 0.5 & 0.2 & 5.7 \\
\hline \multirow{2}{*}{ Site 6} & $6 \mathrm{~h}$ & \multirow{2}{*}{230} & 540 & 590 & \multirow{2}{*}{2200} & \multirow{2}{*}{161} & \multirow{2}{*}{1500} & \multirow{2}{*}{0.9} & \multirow{2}{*}{0.07} & 2.8 \\
\hline & $6 \mathrm{~g}$ & & 390 & 530 & & & & & & 3.9 \\
\hline Site 7 & S7 & 200 & 400 & 960 & 6200 & 510 & 2800 & 0.5 & 0.08 & 7 \\
\hline & & & & $\begin{array}{l}\text { at al } \\
\text { idien }\end{array}$ & $\begin{array}{l}\text { s } Q_{S}= \\
\text { ite } 5:\end{array}$ & $\begin{array}{l}/ 10 \\
z)=\end{array}$ & $\begin{array}{l}S \mathrm{~b}=\infty \\
0+1.312\end{array}$ & & & \\
\hline
\end{tabular}

Fig. 5 Selected mechanical and geometrical parameters in $3 \mathrm{D}$ and $2 \mathrm{D}$ models. $V_{S \min }$ : minimum $\mathrm{S}$-wave velocity, $V_{S 30}$ : time-averaged $S$-wave velocity in the upper $30 \mathrm{~m}, \bar{V}_{S}$ : averaged $\mathrm{S}$-wave velocity in sediments, $W$ : width of sediments at the free surface, $z_{\max }$ : maximum sediment thickness, $V_{S \mathrm{~b}}$ : S-wave velocity in bedrock, $f_{00}$ : the lowest of local fundamental resonant frequencies for a site, i.e., the local fundamental frequency corresponding to free-surface position above $z_{\max }$

performed simulations. An asterisk for each DC point source represents 12 3D simulations - 6 for elementary dipoles in the homogeneous halfspace, 6 for elementary dipoles in the model with a local surface sedimentary structure. Responses for the elementary dipoles make it possible to obtain a response to a DC point source producing a reference accelerogram. An asterisk for a plane-wave (P) excitation represents $33 \mathrm{D}$ simulations in 3D models - each corresponding to one Cartesian polarization of the incident plane wave, $2 \mathrm{P}-\mathrm{SV}$ simulations and $1 \mathrm{SH}$ simulation in 2D models, and 2 simulations in 1D models (one for $\mathrm{P}$, one for $\mathrm{S}$ wave), respectively. The 1D simulations were performed for all considered receiver positions. A local (column) 1D model was considered at each receiver position. Figure 7 shows frequency ranges considered in the FD simulations. An overview of the calculated EGM characteristics is displayed in Fig. 8. As explained in the accompanying article, the EGM characteristics are calculated for a set of selected realistic input accelerograms, in order to get robust estimates on the corresponding average amplification factors (and their signal-to-signal variability). The list of accelerograms is provided in the accompanying article, together with the rationale behind their choice.

\section{Overview of calculated EGM aggravation factors}

For each component of motion the following EGM scalar characteristics are evaluated: $\overline{A F}\{p g a\}$ - average amplification factor for $p g a, \overline{A F}\{p g v\}$-average amplification factor for $p g v, \overline{F_{A}}$ - short-period amplification factor, $\overline{F_{V}}$-long-period amplification factor, $\overline{F_{0}}-$ amplification factor centred about the minimum fundamental resonant frequency $f_{00}, \overline{F_{L}}-$ amplification factor centred about the local fundamental resonant frequency $f_{0}$, $\overline{A F}\left\{a_{r m s}\right\}$-average amplification factor for root-mean-square acceleration, $\overline{A F}\{S I\}$-average amplification factor for spectrum intensity, $\overline{A F}\{C A V\}$-average amplification factor for cumulative absolute velocity, and $\overline{A F}\left\{I_{A}\right\}$-average amplification factor for Arias intensity. For a given position at a site it is reasonable to define a $3 \mathrm{D} / 2 \mathrm{D}$ aggravation factor 


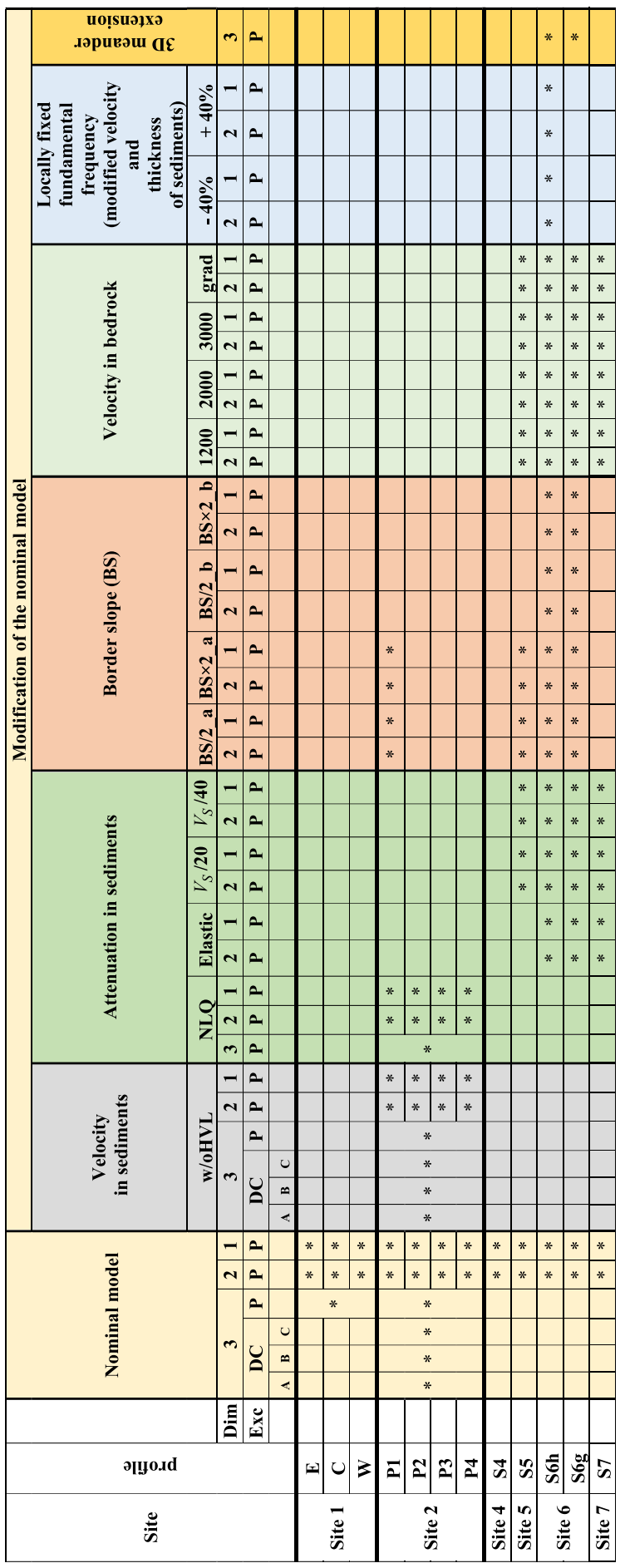

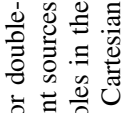

总

茪

ค. 월 3

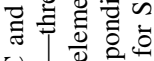

ن

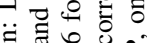

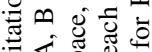

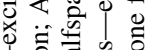

政的

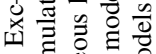

的苋

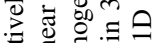

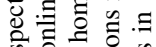

巳 ฏ

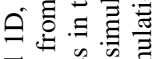

उ す⿺辶一

तิ

A t)

लि

효

$\square$ 릉

洁

-10.

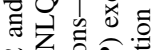

的昰焉

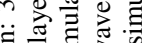

帘的焉

:

듬

.50

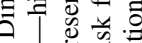

号客

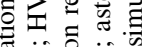

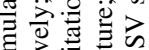

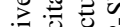

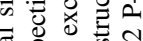

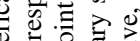

늘

$\supseteq \cup \overline{0}$

娄寻

敋

용

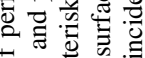

\&

娄䒘苋

os

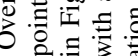

$0 \div \overline{0}$

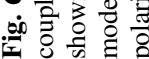




\begin{tabular}{|c|c|c|c|}
\hline \multirow{2}{*}{ Site } & \multirow{2}{*}{ 를 } & \multicolumn{2}{|c|}{ Dimension } \\
\hline & & 3D & 2D \\
\hline \multirow{3}{*}{ Site 1} & $\mathrm{E}$ & \multirow{3}{*}{$0.5-5 \mathrm{~Hz}$} & \multirow{3}{*}{$\begin{array}{l}0.5-5 \mathrm{~Hz} \\
0.2-20 \mathrm{~Hz}\end{array}$} \\
\hline & $\mathrm{C}$ & & \\
\hline & W & & \\
\hline \multirow{4}{*}{ Site 2} & $\mathrm{P} 1$ & \multirow{4}{*}{$0.5-5 \mathrm{~Hz}$} & \multirow{4}{*}{$\begin{array}{l}0.5-5 \mathrm{~Hz} \\
0.2-20 \mathrm{~Hz}\end{array}$} \\
\hline & $\mathrm{P} 2$ & & \\
\hline & P3 & & \\
\hline & P4 & & \\
\hline Site 4 & $\mathrm{~S} 4$ & & $0.2-20 \mathrm{~Hz}$ \\
\hline Site 5 & S5 & & $0.2-20 \mathrm{~Hz}$ \\
\hline \multirow{2}{*}{ Site 6} & S6h & $0.5-7 \mathrm{~Hz}$ & $\begin{array}{l}0.5-7 \mathrm{~Hz} \\
0.2-20 \mathrm{~Hz}\end{array}$ \\
\hline & S6g & $0.5-7 \mathrm{~Hz}$ & $\begin{array}{l}0.5-7 \mathrm{~Hz} \\
0.2-20 \mathrm{~Hz}\end{array}$ \\
\hline Site 7 & S7 & & $0.2-20 \mathrm{~Hz}$ \\
\hline
\end{tabular}

Fig. 7 Frequency ranges for calculations of earthquake ground motion characteristics

as ratio of values of an EGM characteristic obtained from 3D and 2D numerical simulations. Analogously, a 2D/1D aggravation factor compares values of an EGM characteristic obtained from 2D and 1D simulations. We refer to Eq. (62) of the accompanying article by Kristek et al. (2018).

Figure 9a shows aggravation factors of all 10 calculated EGM characteristics for the nominal models at receiver positions at rock outcrop (receiver positions at the free surface outside the sediments in profiles shown in Fig. 4). We can see that significant majority of all values are below level 1.25. This is why we choose this level as a reasonable level above which the value of an aggravation factor is considered significant. An alternative version of the figure is include in the Online material 14. That figures better shows the scatter at receiver positions at rock outcrop. Figure $9 \mathrm{~b}$ shows aggravation factors of all 10 calculated EGM characteristics for the nominal models at receiver positions atop sediments. The table listing the average, median and $90 \%$ percentile amplification factor and the average aggravation factor for each site, each EGM characteristic and each component is in Online material 8. For all sites there is at least one EGM characteristic with "significant" (i.e., larger than 1.25) 2D/1D aggravation factor. Overall 2D/1D aggravation 


\begin{tabular}{|c|c|c|c|c|c|}
\hline \multicolumn{2}{|c|}{$\begin{array}{c}\text { Absolute } \\
\text { EGM } \\
\text { characteristics } \psi\end{array}$} & $\begin{array}{c}\text { Relative } \\
\text { EGM } \\
\text { characteristics }\end{array}$ & $\begin{array}{c}\text { Average } \\
\text { relative EGM } \\
\text { characteristics }\end{array}$ & $\begin{array}{c}\text { Average } \\
\text { amplification } \\
\text { factors }\end{array}$ & $\begin{array}{c}\mathrm{DD} / 1 \mathrm{D}, 3 \mathrm{D} / 2 \mathrm{D} \\
\text { and } 3 \mathrm{D} / 1 \mathrm{D} \\
\text { aggravation } \\
\text { factors }\end{array}$ \\
\hline $\begin{array}{l}p g a \\
p g v \\
C A V \\
I_{A} \\
a_{r m s} \\
S I\end{array}$ & $\begin{array}{l}\text { calculated } \\
\text { for all receiver } \\
\quad \text { positions } \\
\text { for each pair } \\
{\left[s_{\xi, i}(\mathrm{t}), a_{\xi, i}(\mathrm{t})\right]} \\
i=1, \ldots, n \\
\xi \in\{x, y, z\}\end{array}$ & $\begin{array}{c}\text { amplification } \\
\text { factor } \\
A F_{\xi, i}\{\psi\}\end{array}$ & $\begin{array}{l}\text { average }(i) \\
\text { amplification } \\
\text { factor } \\
\frac{A F_{\xi}}{\{\psi\}}\end{array}$ & $\begin{array}{l}\overline{F_{A}} \\
\overline{F_{V}} \\
\overline{F_{0}} \\
\overline{F_{L}}\end{array}$ & $\begin{array}{l}\text { calculated } \\
\text { for all receiver } \\
\text { positions } \\
\text { for } \\
\text { the anti-plane, } \\
\text { in-plane } \\
\text { and } \\
\text { vertical } \\
\text { components }\end{array}$ \\
\hline \multicolumn{6}{|c|}{$\begin{array}{l}S_{D}-\text { relative displacement response spectrum, } p g a-\text { peak ground acceleration } \\
p g v-\text { peak ground velocity, } C A V-\text { cumulative absolute velocity, } I_{A} \text {-Arias intensity } \\
a_{r m s} \text { - root-mean-square acceleration, } S I-\text { spectrum intensity. Averaged amplification factors: } \\
\overline{F_{A}}-\text { short-period, } \overline{F_{V}}-\text { long-period, } \overline{F_{0}}-f_{00} \text {-centred, } \overline{F_{L}}-f_{0} \text {-centred. } f_{0}-\text { a local 1D } \\
\text { fundamental resonant frequency, } f_{00} \equiv \min _{\text {sites }}\left\{f_{0}\right\}\end{array}$} \\
\hline
\end{tabular}

Fig. 8 Overview of the calculated earthquake ground motion characteristics. See the accompanying article (Kristek et al. 2018) for definitions

factors on the anti-plane and in-plane components are comparable while they are considerably larger for the vertical component. All characteristics exhibit significant 2D/1D aggravation factor on the vertical component. This may be understood relatively easily by the fact that the 1D amplification, in the usual vertical plane wave assumption, can be associated only with P-waves for the vertical component: it is therefore controlled by the $\mathrm{P}$-wave velocity profile and can be significant only beyond the P-wave fundamental frequency which is significantly higher than the S-wave fundamental frequency. Conversely, in the real world, the vertical motion does exhibit larger amplitude S-wave phases (unpredictable by classical $1 \mathrm{D}$ approach with vertically incident plane waves), and in the 2D and 3D simulation cases, the vertical motion is strongly affected by both the S-to-P conversions on dipping interfaces (effects similar to oblique incidence on horizontal interfaces), and the edge-generated Rayleigh waves. This strongly suggests that 1D modelling with vertically incident plane waves significantly underestimates ground motion on the vertical component, because it completely ignores the impact of S-waves on vertical motion. The variability of 3D/2D aggravation factors show that $3 \mathrm{D}$ effects are present both in the Grenoble valley (Site 2) and Mygdonian basin (Site 1). However, their values are significantly smaller (and are actually lower than 1 for quite many sites) than the 2D/1D aggravation factor (which are however evaluated on a broader frequency range). Moreover, difference between the 3D/2D aggravation factors on the horizontal components and those on the vertical component is considerably smaller compared to the $2 \mathrm{D} / 1 \mathrm{D}$ factors, which constitutes another indication of the intrinsic limitation (or even flaw) in the 1D, vertically incident plane wave assumption when considering the vertical motion.

We performed a descriptive statistical analysis and used scatter matrices to investigate possible correlations between EGM characteristics in order to focus mostly on independent 
(a)

receivers at rock outcrop

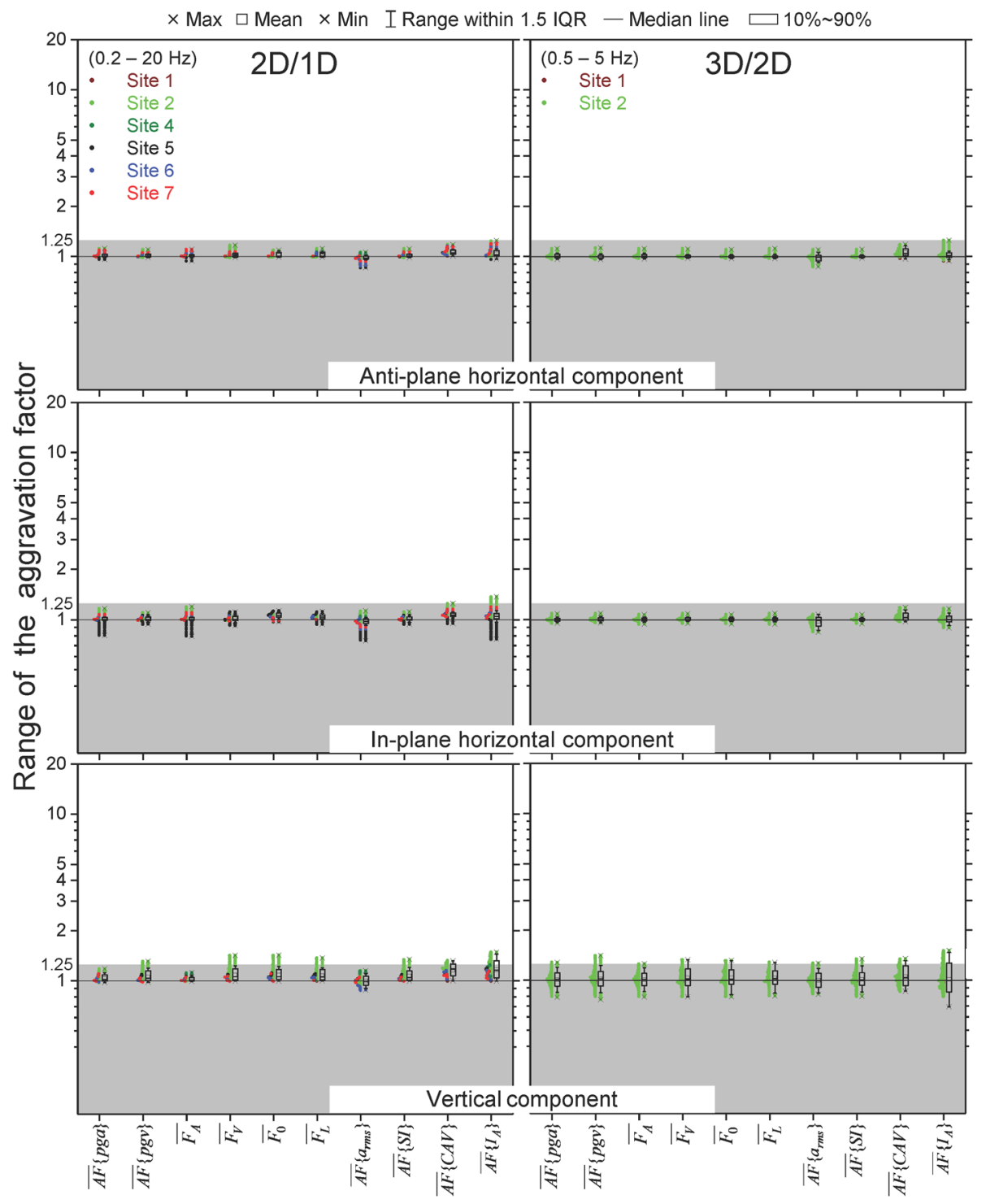

Fig. 9 a 2D/1D and 3D/2D aggravation factors for $10 \mathrm{EGM}$ characteristics calculated for the nominal models. Each point represents a value at one receiver position at rock outcrop. $I Q R$ interquartile range. b The same as (a) but for receiver positions atop sediments. Excluded are receiver positions in case of the local fundamental frequency larger than $20 \mathrm{~Hz}$

ones. The scatter matrices and values of the correlation coefficients make it possible to estimate the level of correlation of all pairs of the aggravation factors. Figure 10 shows correlations of all EGM pairs, considering simultaneously all receivers of all models, for anti-plane component. The same for in-plane and vertical components is in Online material 
(b)

receivers atop sediments

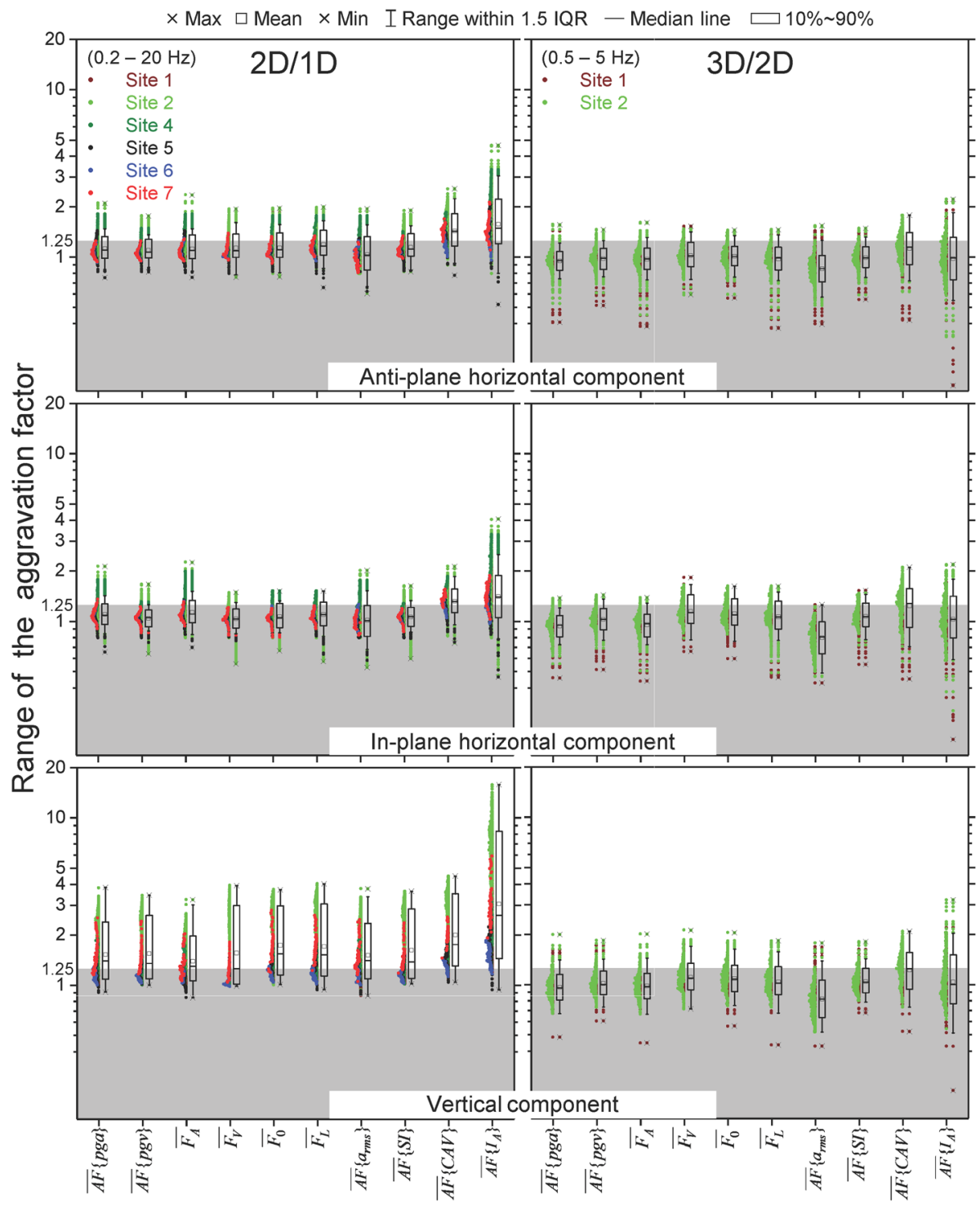

Fig. 9 continued

9 and 10, respectively. For brevity, in the following we symbolically say, e.g., " $\overline{A F}\{p g a\}$ is correlated with $\overline{F_{A}}$ " meaning that the aggravation factor $\overline{A F}\{p g a\}$ is correlated with the aggravation factor of $\overline{F_{A}}$. The analysis led us to the following findings:

a. $\overline{A F}\{p g a\}$ is correlated with $\overline{F_{A}} \cdot \overline{A F}\{p g a\}$ is correlated with other quantities more than $\overline{F_{A}}$ is. Thus, $\overline{A F}\{p g a\}$ will be excluded in the following. 


\section{Correlation of 3D/2D and 2D/1D aggravation factors}

Anti-plane horizontal component

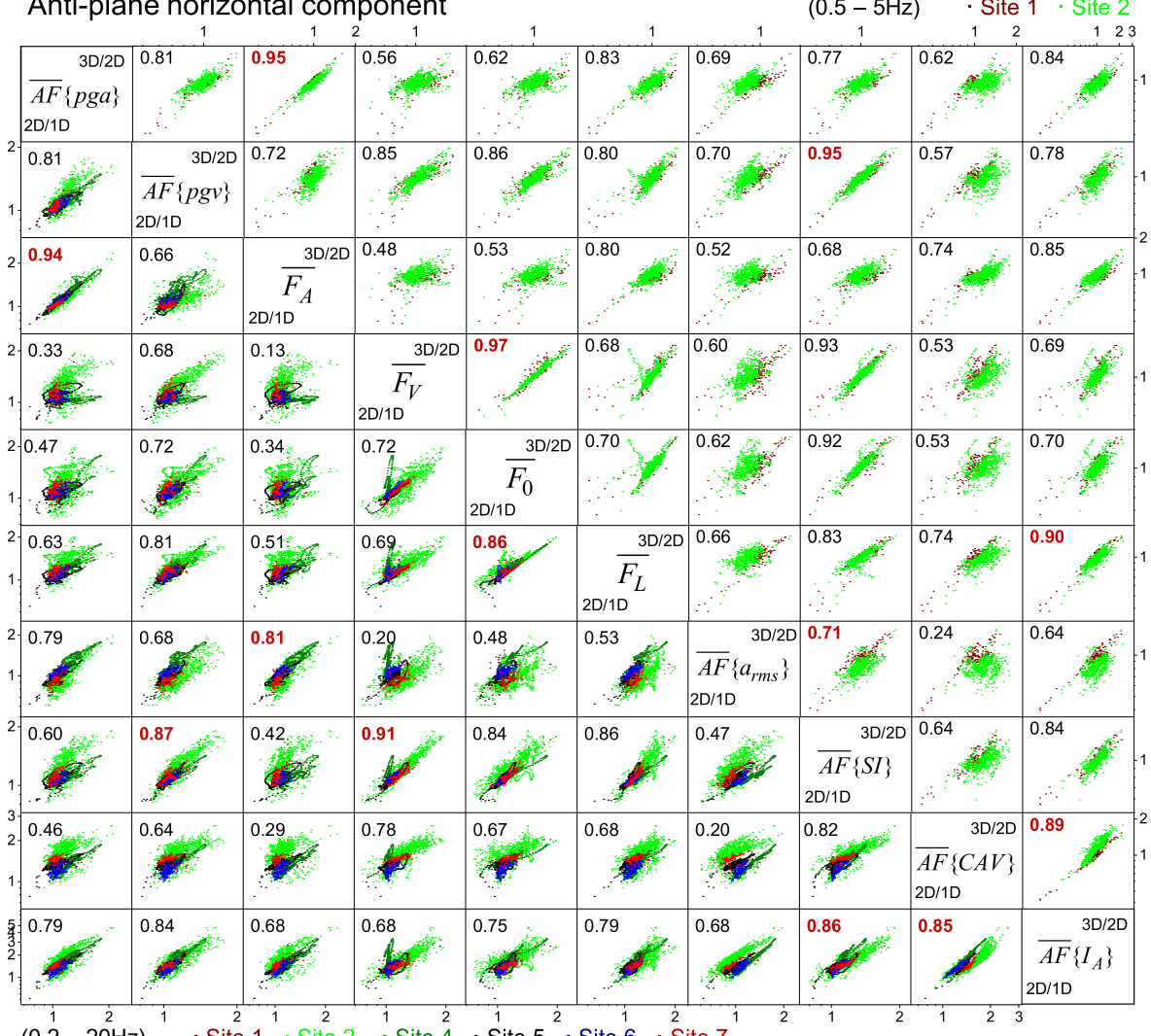

$(0.2-20 \mathrm{~Hz}) \cdot$ Site $1 \cdot$ Site $2 \cdot$ Site $4 \cdot$ Site $5 \cdot$ Site $6 \cdot$ Site 7

Fig. 10 Correlation of the aggravation factors for 10 EGM characteristics for the anti-plane component. Given the symmetry of the scatter matrices, the lower left triangle shows scatter and correlation coefficients of 2D/1D aggravation factors, the upper right triangle shows scatter and correlation coefficients of 3D/2D aggravation factors. The significant correlation is indicated by bold red correlation coefficient

b. $\overline{A F}\{S I\}$ is correlated with $\overline{A F}\{p g v\}$ and also with $\overline{F_{V}}$, which basically means that SI is an intermediate frequency characteristic. As $\overline{A F}\{p g v\}$ and $\overline{F_{V}}$ are more common EGM characteristics, $\overline{A F}\{S I\}$ will be excluded in the following.

c. $\overline{A F}\left\{I_{A}\right\}$ is correlated with $\overline{A F}\{C A V\} . \overline{A F}\left\{I_{A}\right\}$ is correlated with other quantities more than $\overline{A F}\{C A V\}$ is. Thus, $\overline{A F}\left\{I_{A}\right\}$ will be excluded to the benefit of $\overline{A F}\{C A V\}$ as both characteristics take into account in some way both the motion amplitude and its duration.

d. $\overline{A F}\left\{a_{r m s}\right\}$ is correlated with $\overline{F_{A}}$ mainly for values of aggravation factor larger than 1.25. $\overline{F_{A}}$ is kept due to correlation with $\overline{A F}\{p g a\}$. Thus, $\overline{A F}\left\{a_{r m s}\right\}$ will be excluded.

e. $\overline{F_{0}}$ is correlated with $\overline{F_{L}} \cdot \overline{F_{0}}$ is more artificial (less founded) quantity since it is not related to the considered receiver, but the whole valley. Thus, $\overline{F_{0}}$ will be excluded.

f. $\overline{A F}\{p g v\}$ is correlated with $\overline{F_{V}}$ and $\overline{F_{L}} \cdot \overline{F_{V}}$ and $\overline{F_{L}}$ are less correlated. Thus, $\overline{A F}\{p g v\}$ will be excluded. 
The scatter matrices and values of the correlation coefficients for the 2D or 3D amplification factors (shown in Kristek et al. 2015) are largely consistent with those obtained for the aggravation factors. Consequently, we further focused our investigations and results on the four EGM characteristics that exhibit (in average, all components considered) the lowest correlations, i.e. those corresponding to $\overline{F_{A}}, \overline{F_{V}}, \overline{F_{L}}$ and $\overline{A F}\{C A V\}$. The two first are short- and intermediate-period characteristics which are more and more often used in earthquake engineering for common constructions (Borcherdt 1994, 2002; Paolucci and Smerzini 2017). The third one focuses on the behaviour around the site fundamental frequency $f_{0}$, a characteristic that is more and more often proposed for site classification (Castellaro et al. 2008; Luzi et al. 2011; Cadet et al. 2012; Pitilakis et al. 2012, 2013). The fourth one is used as an index related to potential damage in nuclear engineering and to soil liquefaction, and was found by Campbell and Bozorgnia (2010) as providing the NGA GMPEs with the lowest aleatory variability values, i.e., as the "best predictable" ground motion characteristic.

\section{Example results: aggravation factors for cumulative absolute velocity}

Here we display and discuss $2 \mathrm{D}$ and $3 \mathrm{D}$ effects using the aggravation factors for one example EGM characteristic $\overline{A F}\{C A V\}$ shown in Figs. 11, 12 and 13. It is obvious from Fig. 11a that the 2D/1D aggravation factor is significant on all components at all receivers atop sediments. As can be seen on Fig. 11a, the aggravation factors at receivers at the rock outcrop are not larger than 1.25 (except those along the western part of profile P2 and profile P1). As pointed out before for the aggravation factors for all EGM characteristics, the aggravation factors on the vertical component are significantly larger than those on the horizontal components. The mean and median values of the aggravation factors on the inplane component are smaller than those on the anti-plane component. The aggravation factors are not related to the shape ratio or velocity contrast in a simple way. The very small shape ratio of the profiles E, C and W in the Mygdonian basin (Site 1) is the reason why the 2D/1D aggravation factors are not larger despite the largest velocity contrast. However, we consider that we do not have a sufficient number of sites, i.e. models, to attempt deriving a dependence of amplification and aggravation factors on both the shape ratio and velocity contrast, as it also depends on the receiver position within a given valley. The important partial conclusion is that $1 \mathrm{D}$ simulations are not sufficient for any of the investigated sites, as there always exist some surface positions for which the aggravation factor significantly exceeds 1.25 .

Analogous figures for $\overline{F_{A}}, \overline{F_{V}}$ and $\overline{F_{L}}$ (shown in the Online material 11-13) reveal similar features except that mean and median values of the aggravation factors on the horizontal components are smaller than those for $\overline{A F}\{C A V\}$.

Figure 11b shows 3D/2D aggravation factors for $\overline{A F}\{C A V\}$-again separately for the sediment sites and rock sites. 3D effects are significant in the Grenoble valley (Site 2)profiles P1-P4, in blue. 3D effects are present also in the Mygdonian basin but they are not dominant. Unlike the $2 \mathrm{D} / 1 \mathrm{D}$ aggravation factors, the vertical component is not significantly different from the horizontal components: the impact of the S-to-P conversions and edge-generated Rayleigh waves is included in both 2D and 3D simulations, while it is not in 1D simulations.

Analogous figures for $\overline{F_{A}}, \overline{F_{V}}$ and $\overline{F_{L}}$ (not shown here) reveal similar features. 

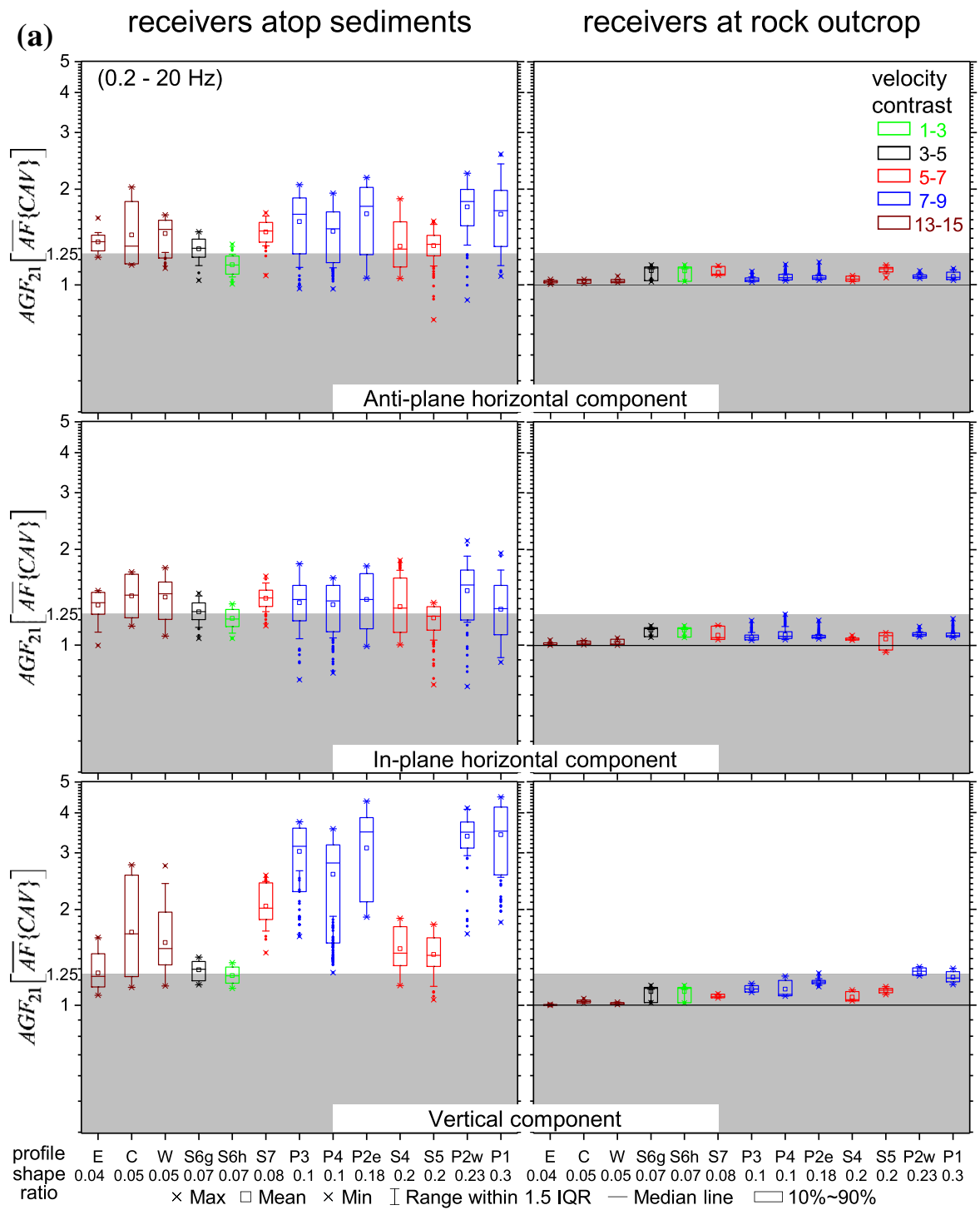

Fig. 11 a 2D/1D aggravation factor for $\overline{A F}\{C A V\}$ for all profiles ordered according to the value of the shape ratio (maximum sediment thickness over width). An additional colour code is provided as an index for the sediment/bedrock velocity contrast. Frequency range: $0.2-20 \mathrm{~Hz}$. b 3D/2D aggravation factor for $\overline{A F}\{C A V\}$ for all profiles ordered according to the value of the shape ratio (maximum sediment thickness over width). Frequency range: $0.5-5 \mathrm{~Hz}$

Figures 12 and 13 detail the values of the aggravation factors along profiles P1 and P4 in the Grenoble valley, Site 2, respectively (see Fig. 2 for the location of 2D profiles). Figure 12 shows that the 3D effects along profile P1 are not negligible (i.e., aggravation factors larger than 1.25) despite the intuitive impression that the profile might be suitable for $2 \mathrm{D}$ modelling. This is clear not only from the values of the aggravation factor but also from the fact that the aggravation-factor curve does not simply reflect the geometry of 

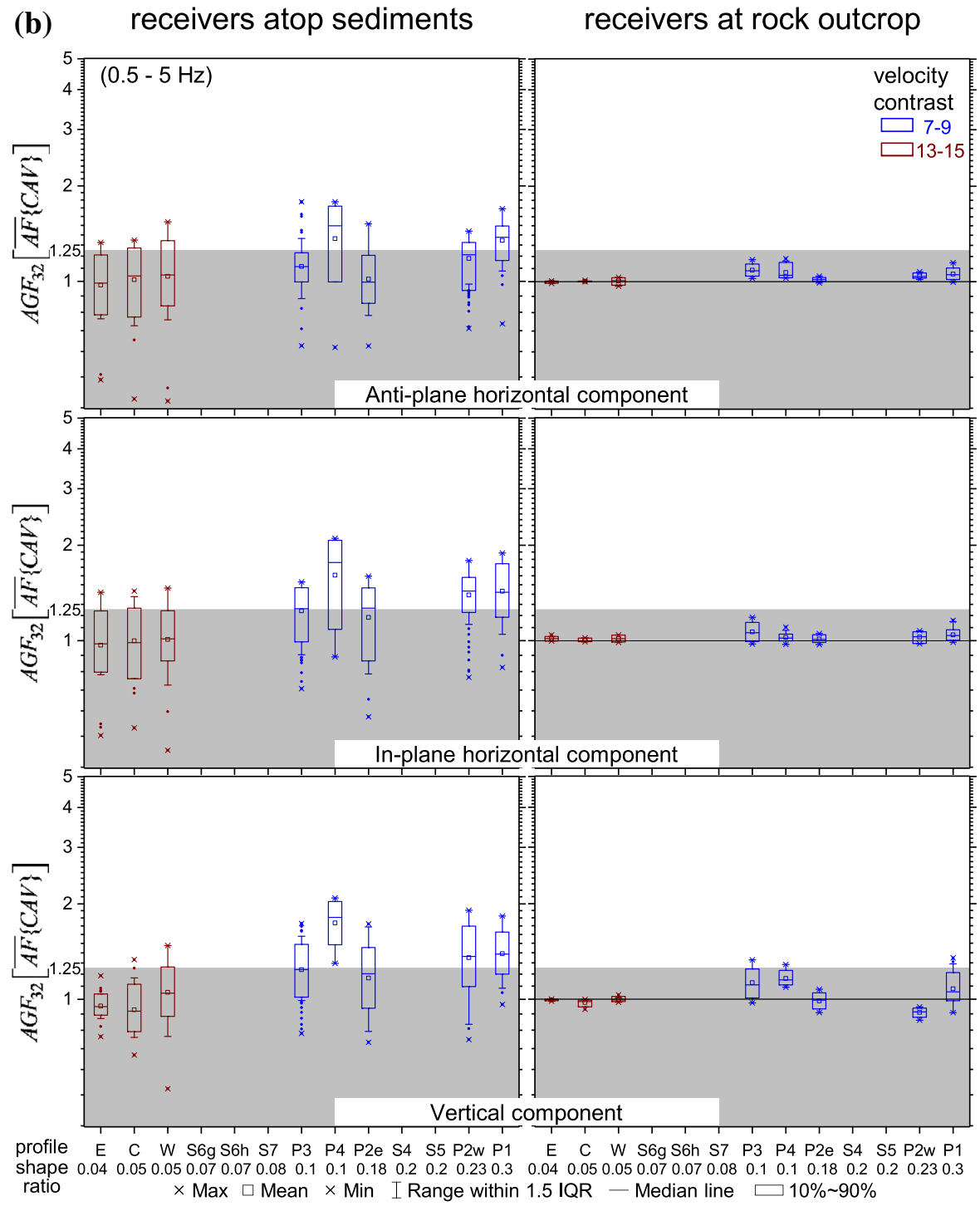

Fig. 11 continued

the profile itself. The 2D/1D aggravation factor on the vertical component is again significantly larger than those on the horizontal components. Such difference is not seen in the $3 \mathrm{D} / 2 \mathrm{D}$ aggravation factors. Figure 13 confirms that $3 \mathrm{D}$ effects are significant along profile $\mathrm{P} 4$-as we could intuitively expect from the sediment-bedrock interface geometry in that part of the valley - see the position of profile P4 at the intersection of three valley branches in Fig. 2. 


\section{$\mathrm{P} 10.5-5 \mathrm{~Hz}$}
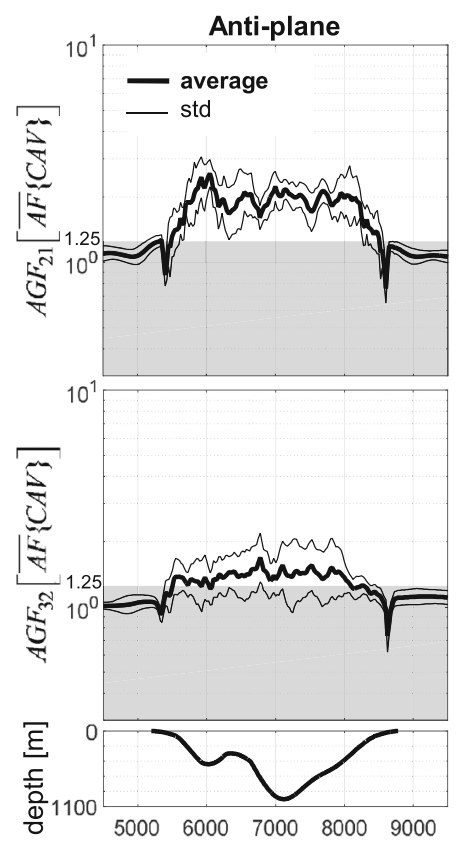
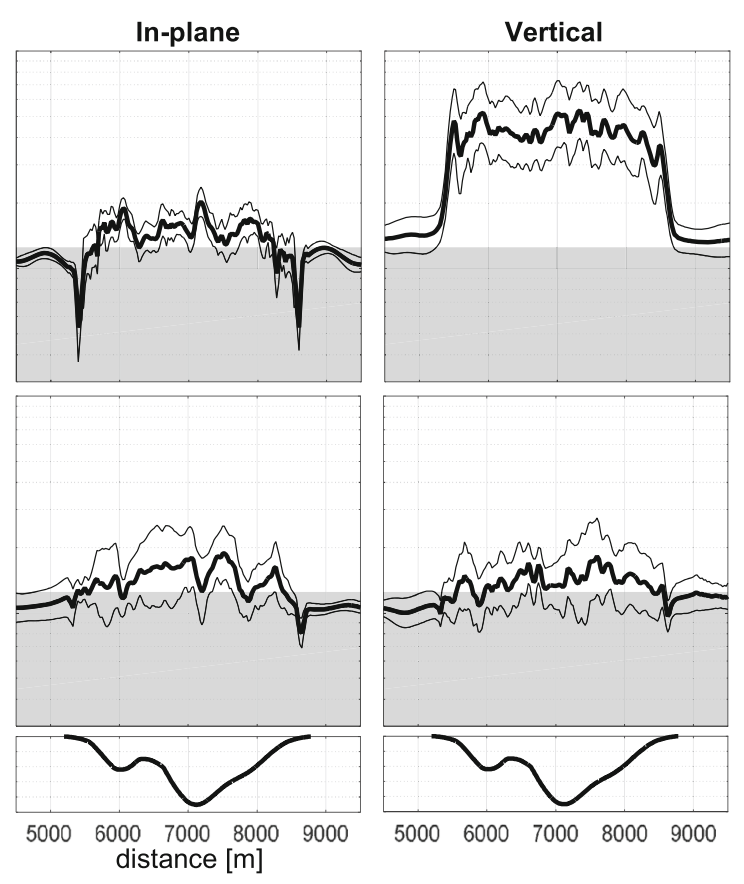

Fig. $123 \mathrm{D} / 2 \mathrm{D}$ (lower panel) and 2D/1D (upper panel) aggravation factors for $\overline{A F}\{C A V\}$ along profile P1 in the Grenoble valley, Site 2. Note that here we show the 2D/1D factor only up to $5 \mathrm{~Hz}$ for comparison with the $3 \mathrm{D} / 2 \mathrm{D}$ factors

\section{Major results from the sensitivity analysis}

As indicated in Fig. 6, several "variants" were considered for each site to further investigate the impact of several geomechanical parameters on the amplification and aggravation factors. Rather than detailing the results for each site, we group below the sensitivity results according to different subsurface parameters, starting with velocity in bedrock and sediments, then addressing the effect of sediment attenuation, and finally considering the effects of subsurface geometry (coupled thickness and velocity variations, edge slopes and $3 \mathrm{D}$ effects in meander-type quasi-cylindrical valleys). In each case, we display results only for one or two EGM characteristics from the four preselected ones.

Effect of variation in bedrock velocity Figure 14a summarizes the bedrock velocity values in the nominal and modified models for Sites 5-7. We considered both cases of constant velocity and non-linear velocity increase in bedrock: the latter case leads to reduced impedance contrast on valley edges compared to valley centre, and may thus significantly impact the edge diffraction effects. Compared to the nominal model, the velocity gradient leads to significantly reduced contrast over the whole valley for Sites 6 and 7 , and for the valley edges for Site 5 (corresponding to sediment thickness less than about $200 \mathrm{~m}$ ). The effects of variations in bedrock velocity are illustrated in Fig. 14b for the EGM characteristic $\overline{F_{L}}$ by the "normalized aggravation factor": for each receiver of each site, the aggravation factor corresponding to a specific bedrock velocity model is divided by the aggravation factor for the same receiver and nominal model. The 
P4 $0.5-5 \mathrm{~Hz}$

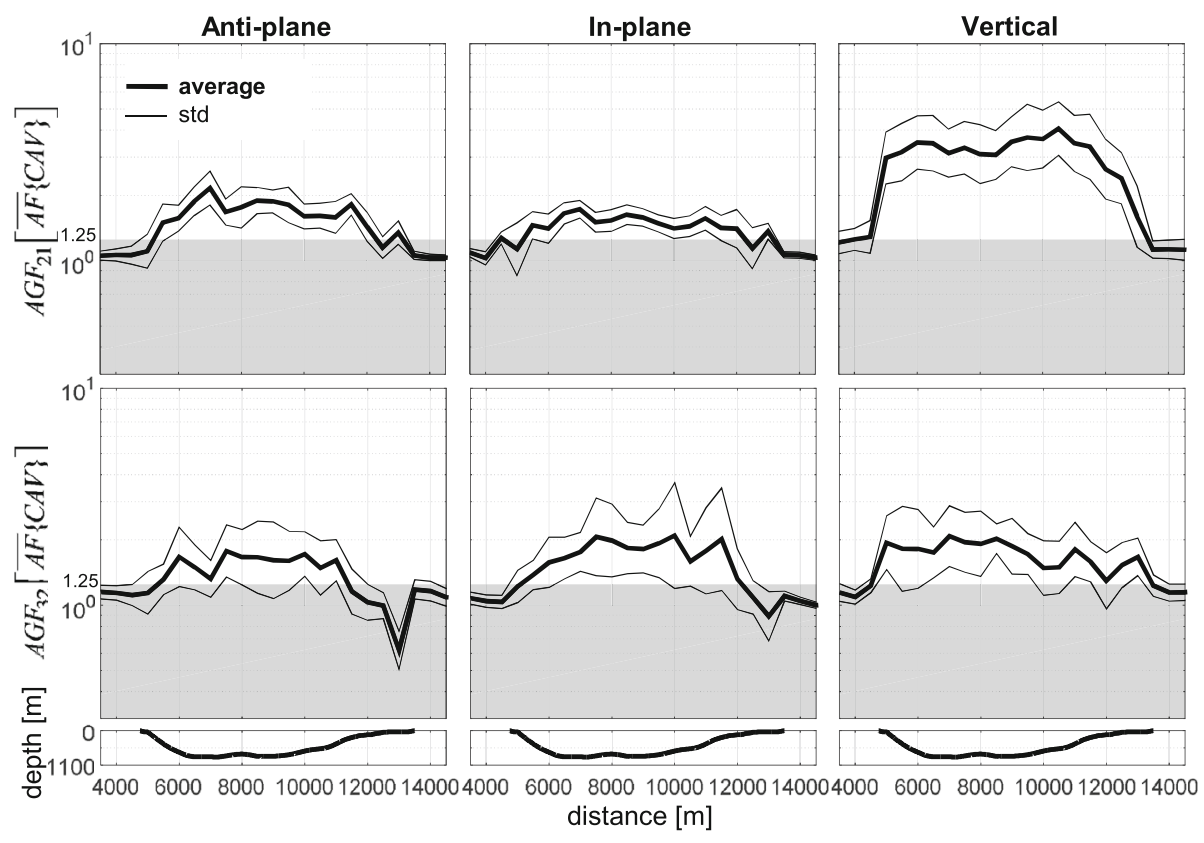

Fig. 13 3D/2D (lower panel) and 2D/1D (upper panel) aggravation factors for $\overline{A F}\{C A V\}$ along profile $\mathrm{P} 4$ in the Grenoble valley, Site 2. Note that here we show the 2D/1D factor only up to $5 \mathrm{~Hz}$ for comparison with the $3 \mathrm{D} / 2 \mathrm{D}$ factors

aggravation factors increase with the impedance contrast at deeper part of the sedimentbedrock interface, and this increase is larger for the vertical component (this is also true for the amplification factors-not shown here). This is mainly true at frequencies close to the fundamental resonant frequency, which is the main reason why the results are shown here for $\overline{F_{L}}$.

Effect of sediment velocity Figure 15 compares 3D/2D and 2D/1D aggravations factors for two models of the Grenoble valley (Site 2)—one without the high-velocity layer in sediments near the free surface and the other with the layer (nominal model). The grey strip indicates the scatter within \pm standard deviation for the nominal model. The scatter corresponds to the variability of the input motion. It is clear that the effect of presence of the high-velocity surface layer in the Site-2 model on the 3D/2D and 2D/1D aggravation factors is negligible for the aggravation factor. The same is true about the amplification factors.

The difference between the velocity distributions in sediments in models S6h (homogeneous) and S6g (gradient) has no effect on the 2D/1D aggravation factor, while it does imply a small difference in the amplification factors for S6h and S6g, which can be attributed to the difference in the impedance contrast at the sediment-bedrock interface (due to different velocity distribution in sediments), see Fig. 16.

Effect of attenuation in sediments Values of EGM characteristics are unrealistically large if attenuation is neglected, and the corresponding results are therefore not shown here. Figure 17 compares the amplification for $C A V$ and aggravation factors for $\overline{A F}\{C A V\}$ for the nominal and modified models of Sites 5-7. Note that an increase/decrease of 
(a)

\begin{tabular}{|c|c|c|c|c|c|}
\hline model & $\begin{array}{l}\text { wave } \\
\text { speed }\end{array}$ & Site 5 & Site $6 \mathrm{~g}$ & Site $6 \mathrm{~h}$ & Site 7 \\
\hline \multirow{2}{*}{ nominal } & $V_{S}$ & $V_{S \mathrm{~b}}(z)=1050+1.3125 z$ & \multicolumn{2}{|c|}{1500} & 2400 \\
\hline & $V_{P}$ & $V_{P \mathrm{~b}}(z)=2300+2.125 z$ & \multicolumn{2}{|c|}{4000} & 4850 \\
\hline \multirow{2}{*}{ BV-1200 } & $\overline{V_{S}}$ & \multicolumn{4}{|c|}{1200} \\
\hline & $V_{P}$ & \multicolumn{4}{|c|}{2400} \\
\hline \multirow{2}{*}{ BV-2000 } & $V_{S}$ & \multicolumn{4}{|c|}{2000} \\
\hline & $V_{P}$ & \multicolumn{4}{|c|}{3460} \\
\hline \multirow{2}{*}{ BV -3000} & $V_{S}$ & \multicolumn{4}{|c|}{3000} \\
\hline & $V_{P}$ & \multicolumn{4}{|c|}{5190} \\
\hline \multirow{2}{*}{ BV-grad } & $V_{S}$ & \multicolumn{4}{|c|}{$V_{S \mathrm{~b}}(z)=680+2520\left(1-e^{-z / 700}\right)$} \\
\hline & $V_{P}$ & \multicolumn{4}{|c|}{$V_{P \mathrm{~b}}(z)=1.73\left[680+2520\left(1-e^{-z / 700}\right)\right]$} \\
\hline
\end{tabular}

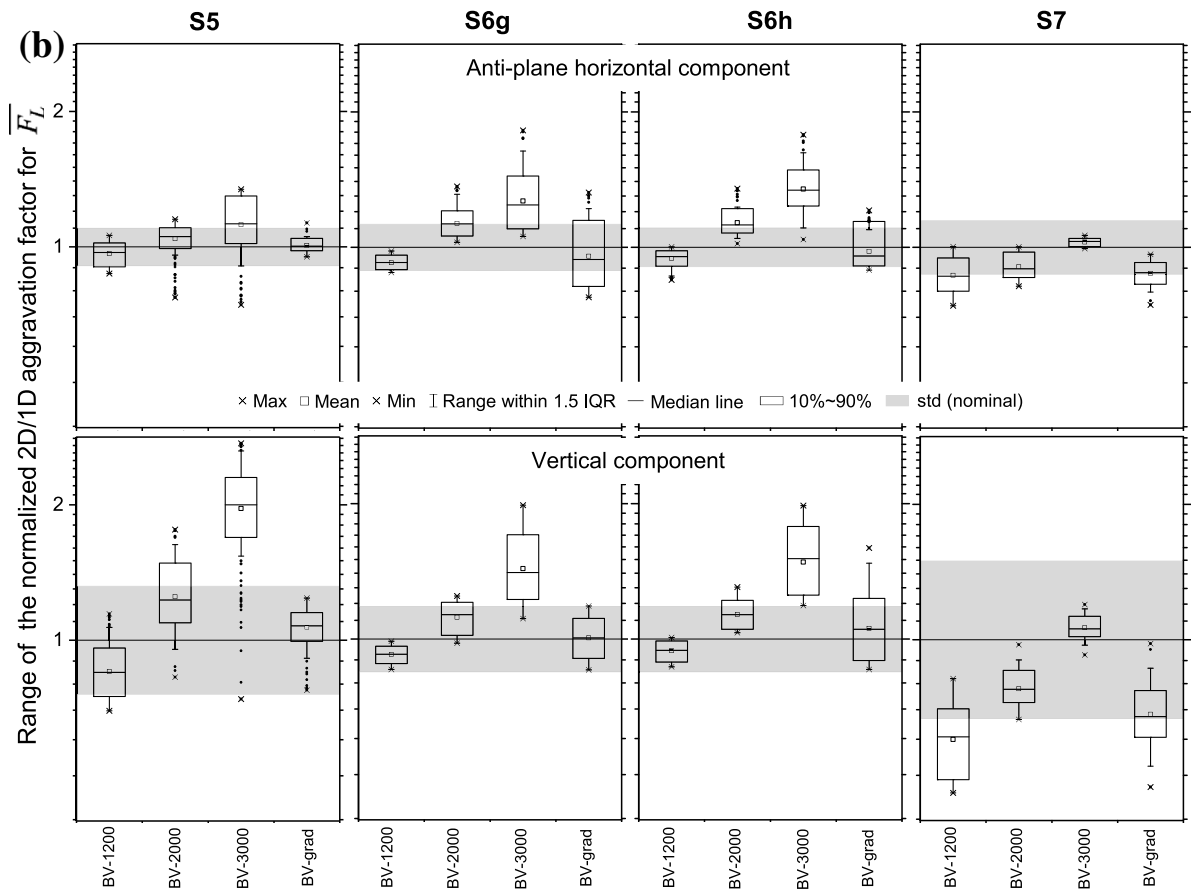

Fig. 14 a Bedrock velocities in the modified models of Sites 5-7 for sensitivity analysis. b 2D/1D aggravation factor for $\overline{F_{L}}$ for modified models of Sites 5-7 illustrating effect of the bedrock velocity 


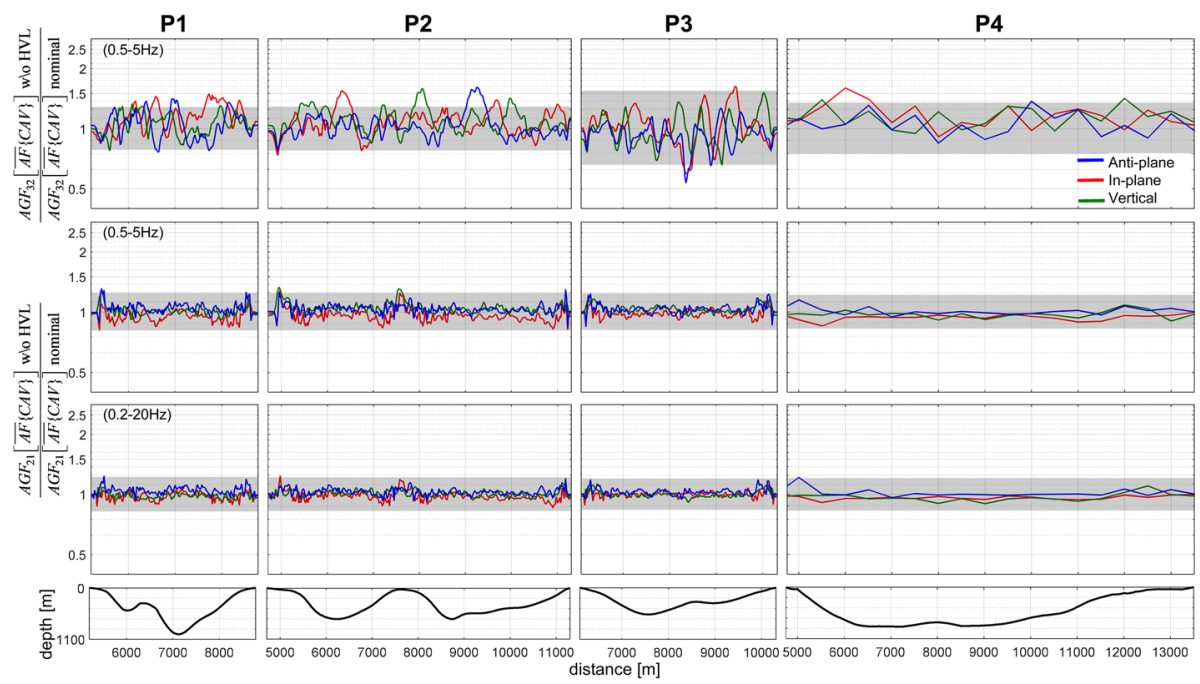

Fig. 15 Ratios of 3D/2D (top panel) and 2D/1D (middle and bottom panels) aggravation factors for $\overline{A F}\{C A V\}$ comparing the nominal model and the modified model without high-velocity layer for profiles at Site 2. The 2D/1D aggravation factor are shown for two frequency ranges - one relevant for 3D simulations, the other for $2 \mathrm{D}$ and $1 \mathrm{D}$ simulations

attenuation of $\mathrm{S}$ waves also means an increase/decrease of attenuation of $\mathrm{P}$ waves because $Q_{\kappa}=\infty$. As expected, the amplification factor decreases with increasing attenuation because of the increased energy dissipation in sediments, which lessens the effect of wave trapping. The 2D/1D aggravation factor also decreases with increasing sediment attenuation, as expected since the "over-amplification" in $2 \mathrm{D}$ valleys is related to the generation and propagation of surface waves, the propagation of which is sensitive to sediment attenuation. However this decrease of the aggravation factor is slightly less sensitive to variations in the attenuation than the amplification factor for horizontal components, since the $1 \mathrm{D}$ response is also significantly reduced by increased attenuation. The case of the vertical component is more complicated, since the $1 \mathrm{D}$ amplification is very mild, and the reduction in aggravation factor is slightly larger than for the horizontal components, and concerns a larger range of values.

We performed simulation only for one alternative attenuation model in $3 \mathrm{D}$-for the Grenoble valley. Therefore we do not have sufficient sensitivity results for 3D. However, that sole simulation provides results similar to those seen based on $2 \mathrm{D}$ simulations: larger attenuation leads to a smaller aggravation factor (Kristek et al. 2015).

Effect of the simultaneous variation in velocity and thickness of sediments Figure 18 compares the amplification for $C A V$ and aggravation factors for $\overline{A F}\{C A V\}$ for the nominal and modified models of Site $6 \mathrm{~h}$. In one modified model the velocity in the homogeneous sediments is increased by $40 \%$, in the other the velocity is decreased by $40 \%$ while the local sediment thickness is increased/decreased by $40 \%$, respectively, in order to keep the local 1D fundamental resonant frequency unchanged at each receiver. The 2D/1D aggravation factors are slightly less sensitive to modifications in both velocities and thicknesses of sediments than the amplification factors are (note the ranges of values in the upper and lower panels). The increase of the impedance contrast in the $V_{S} \& h-40 \%$ modification causes the increase in the amplification factor. The opposite "polarity" for the vertical 
Site $6 \quad 0.2-20 \mathrm{~Hz}$
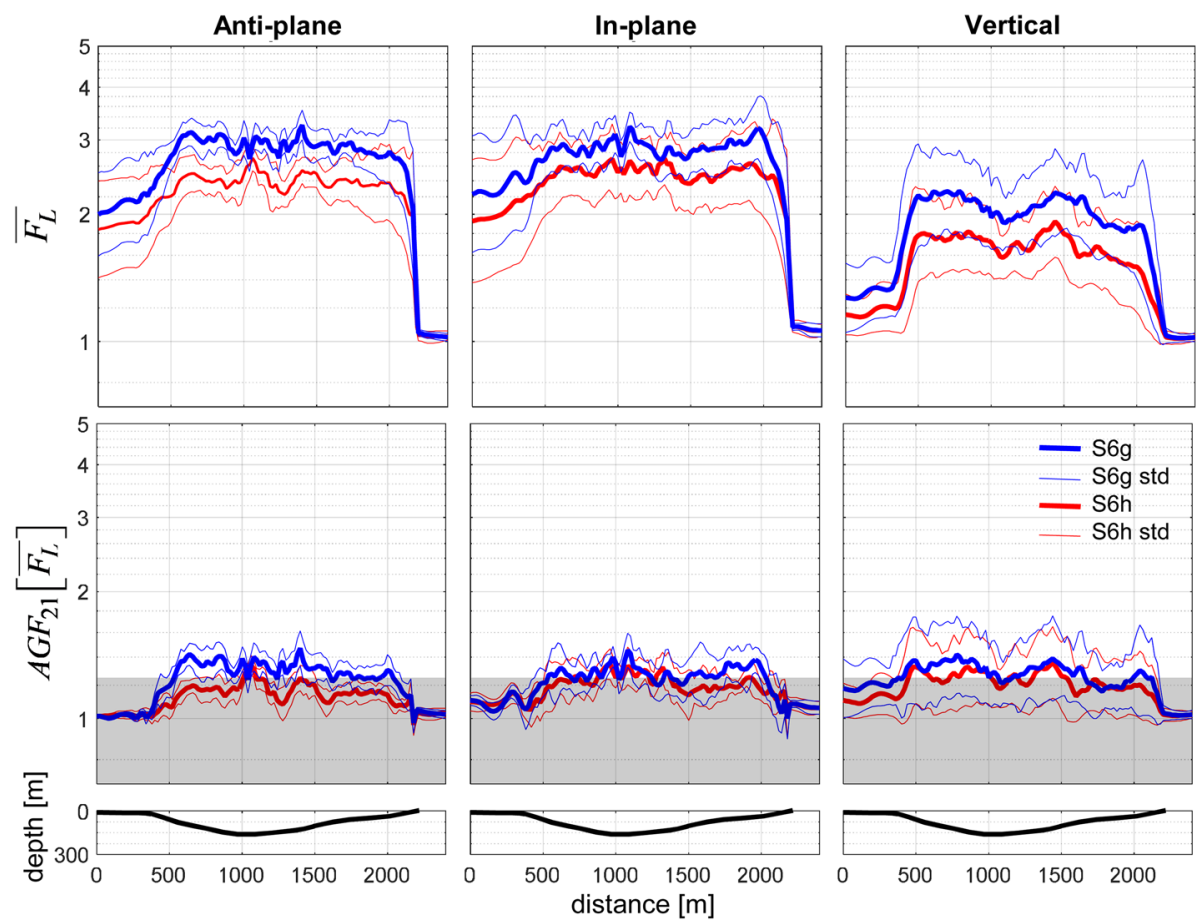

Fig. $16 \overline{F_{L}}$ and 2D/1D aggravation factor for $\overline{F_{L}}$ for models S6h and S6g of Site 6 illustrating the effect of velocity distribution in sediments

component as compared with the horizontal component (i.e., lower amplification factor and aggravation factors for decreased $V_{S}$ and $h$ ) is due to the fact that P-wave velocity is unchanged in the modified models, and also corresponds to high Poisson ratio, with the lowest amplification and aggravation factors of the all sites for the vertical component: the effect of the edge slope prevails for the amplification of the vertical component.

Effect of geometry of the border slope The effects of the border-slope geometry on the amplification factor for $C A V$ and aggravation factor for $\overline{A F}\{C A V\}$ are illustrated in Fig. 19. The effect of the border slope is evident close to the valley border for the amplification factor as it significantly modifies the thickness of the local soil columns, but it is insignificant away from the border, and does not impact the aggravation factor. Note that this conclusion is consistent with that by Moczo et al. (1996).

Effect of the 3D meander-like extension Models S6h and S6g were extended to 3D meander-like model. Figure 20 shows 3D/2D aggravation factors for $\overline{A F}\{C A V\}$ for 25 profiles in the 3D model of the meander-like extension of the nominal $2 \mathrm{D}$ models $\mathrm{S} 6 \mathrm{~h}$ and S6g of Site 6. It is obvious that the aggravation factors are within the \pm standard deviation of the 2D amplification factor. (Again, the standard deviation represents the variability of the input motion.) In other words, the particular meander-type geometry does not impact much the response for the investigated frequency range of $[0.5,7] \mathrm{Hz}$ assuming a planewave incidence, at least as long as the sinuosity/curvature of the river remains comparable with what is considered here. 

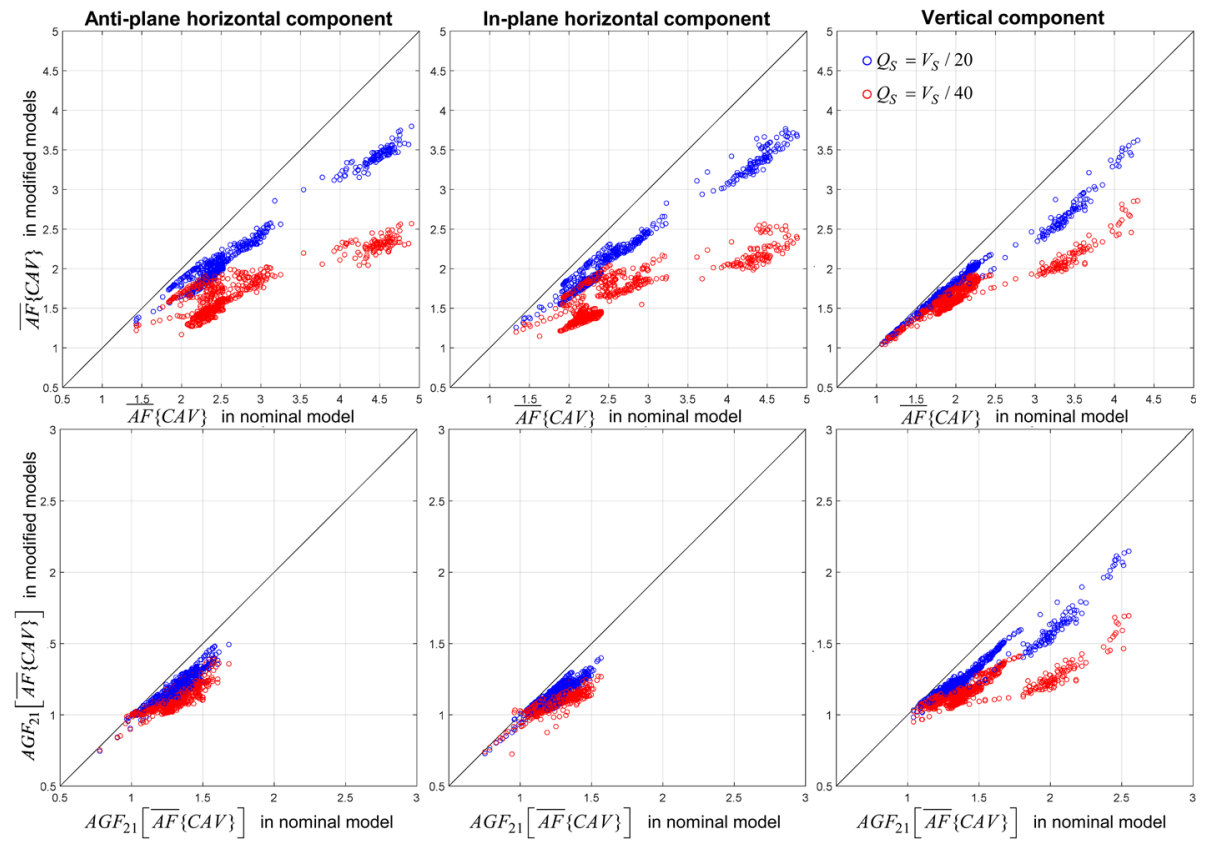

Fig. 17 Comparison of the 2D amplification for $C A V$ and 2D/1D aggravation factors for $\overline{A F}\{C A V\}$ in the modified and nominal models of Sites 5-7 illustrating the effect of level of attenuation. Note that one symbol (empty circle) is used for all receiver positions at all sites

Effect of the wavefield excitation Figure 21a and b compare the amplification factors computed for three different locations of point sources to the corresponding values for the vertically incident plane waves. This limited numerical experience indicates that the usual, and simple vertically incident plane wave assumption allows to obtain robust estimates of the amplification factors with respect to those obtained for DC point sources with specific hypocentral positions. If the knowledge about location of potential seismic sources is very poor an additional variability in site response $( \pm 10 \%)$ could be considered. The sensitivity to (point) source position remains smaller than the sensitivity to the characteristics of the input signal.

\section{Conclusions}

We performed 3D simulations for 3 3D local surface sedimentary structures (one of them being an artificial/virtual 3D extension of a 2D structure), 2D simulations for $122 \mathrm{D}$ crosssections ( 7 of them being selected 2D profiles in the 3D structures), and 1D simulations for local 1D models in the 2D models. Using pseudoimpulse responses from direct finitedifference simulations and a set of specified 11 reference accelerograms we investigated the amplification and aggravation factors in the specified local "nominal" sedimentary structures in terms of average (over the 11 reference accelerograms) amplification and aggravation factors for several EGM characteristics. In addition, the effects of uncertainty in the bedrock velocity, velocity in sediments, attenuation in sediments, interface geometry and simultaneous variations in velocity and thickness of sediments was investigated 

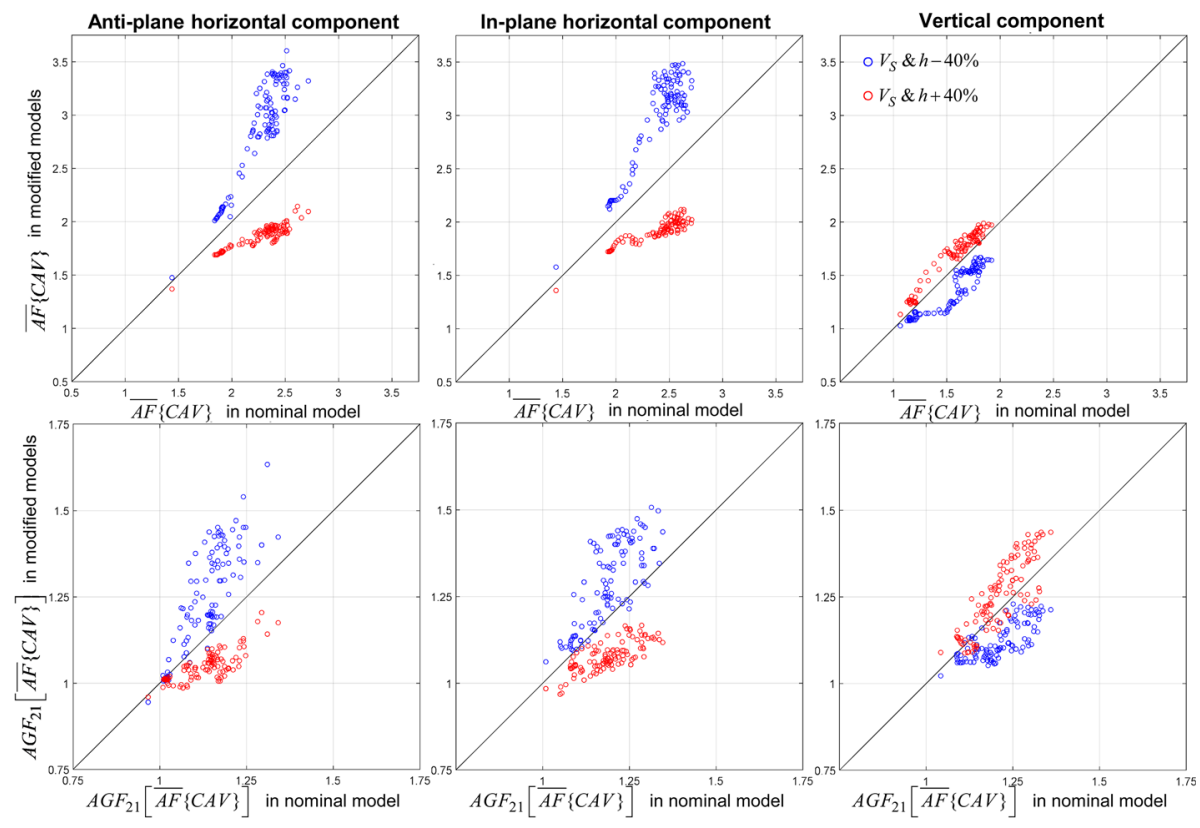

Fig. 18 Comparison of the 2D amplification for $C A V$ and 2D/1D aggravation factors for $\overline{A F}\{C A V\}$ in the modified and nominal models of Sites 6 illustrating the effect of the simultaneous variations in the velocity and thickness of sediments with a fixed value of the local 1D fundamental resonant frequency

through sensitivity studies by varying the mechanical or geometrical parameters around their nominal values.

The values of amplification and aggravation factors depend on the considered EGM characteristic: largest values are found for the Arias intensity $I_{A}$, ahead of the cumulative absolute velocity $C A V$, lowest values are found for root mean square acceleration. An analysis of ground motion on the rocky valley edge sites indicates the existence of some feedback effects which slightly modify the "free-field" rock motion; however, the associated ground modifications remain most often smaller than 20-25\%, even for the most sensitive EGM characteristics. We have therefore considered as "significant" all the valley effects resulting in aggravation factor larger than 1.25.

For all the considered sites, there is at least one surface point for which at least one EGM characteristic exhibits a significant 2D/1D aggravation factor (i.e., larger than 1.25). In particular, all EGM characteristics exhibit significant $2 \mathrm{D} / 1 \mathrm{D}$ aggravation factor on the vertical component.

The 2D/1D aggravation actors are component dependent: they are found systematically the largest for the vertical component, and the smallest for the in-plane component. For the anti-plane case, there is no component-to-component exchange of energy, while for the inplane case, the generation of Rayleigh waves on valley edges, together with the SV to P and (to a less extent) $\mathrm{P}$ to SV conversions, result in a partitioning of energy on the two components, leading to larger aggravation factors on vertical component, and lower ones on the in-plane component. Such a large sensitivity of amplification of vertical ground motion to the 2D (or 3D) underground structure should be kept in mind for the design of structures or equipment which should be designed for vertical motion (such as bridges or overhead cranes), especially as a large majority of the structural engineering community 

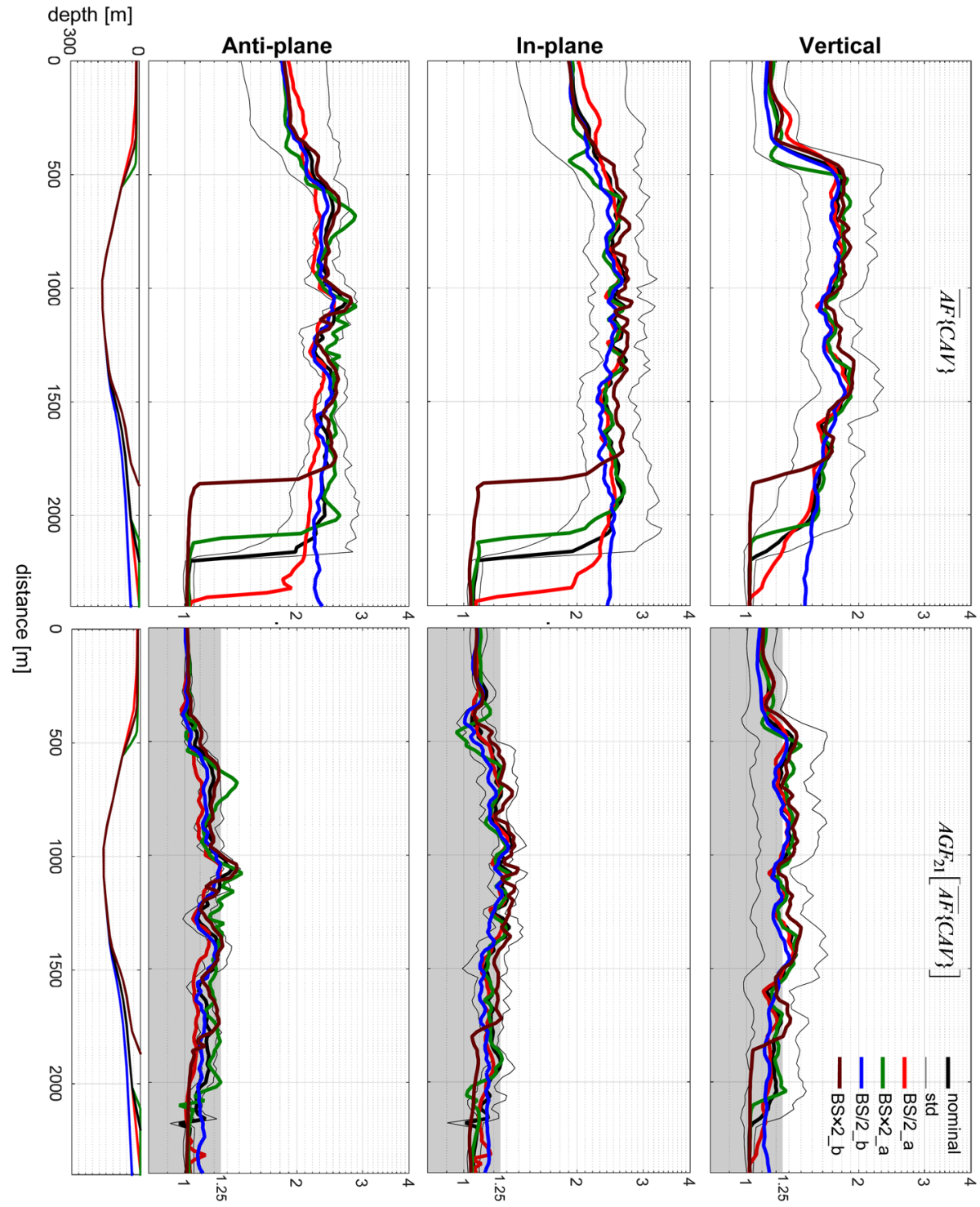

Fig. 19 Amplification for $C A V$ and aggravation factors for $\overline{A F}\{C A V\}$ in the modified and nominal models of Sites $6 \mathrm{~h}$ illustrating the effect of border-slope geometry. BS/2_a and BSx2_a indicate twice steeper and twice less steeper border slopes, respectively. BS/2_b and BSx2_b indicate analogous variation of slope angles but only on the right-hand side border. The grey strip corresponds to the level above which the value of an aggravation factor is considered significant

considers there is no amplification for vertical motion on soft soils (see for instance the recommended design spectra in EC8 regulations). The latter is in our opinion a direct consequence of the traditional 1D modelling approach considering only vertically incident plane waves: for the vertical component it should be supplemented with the consideration 


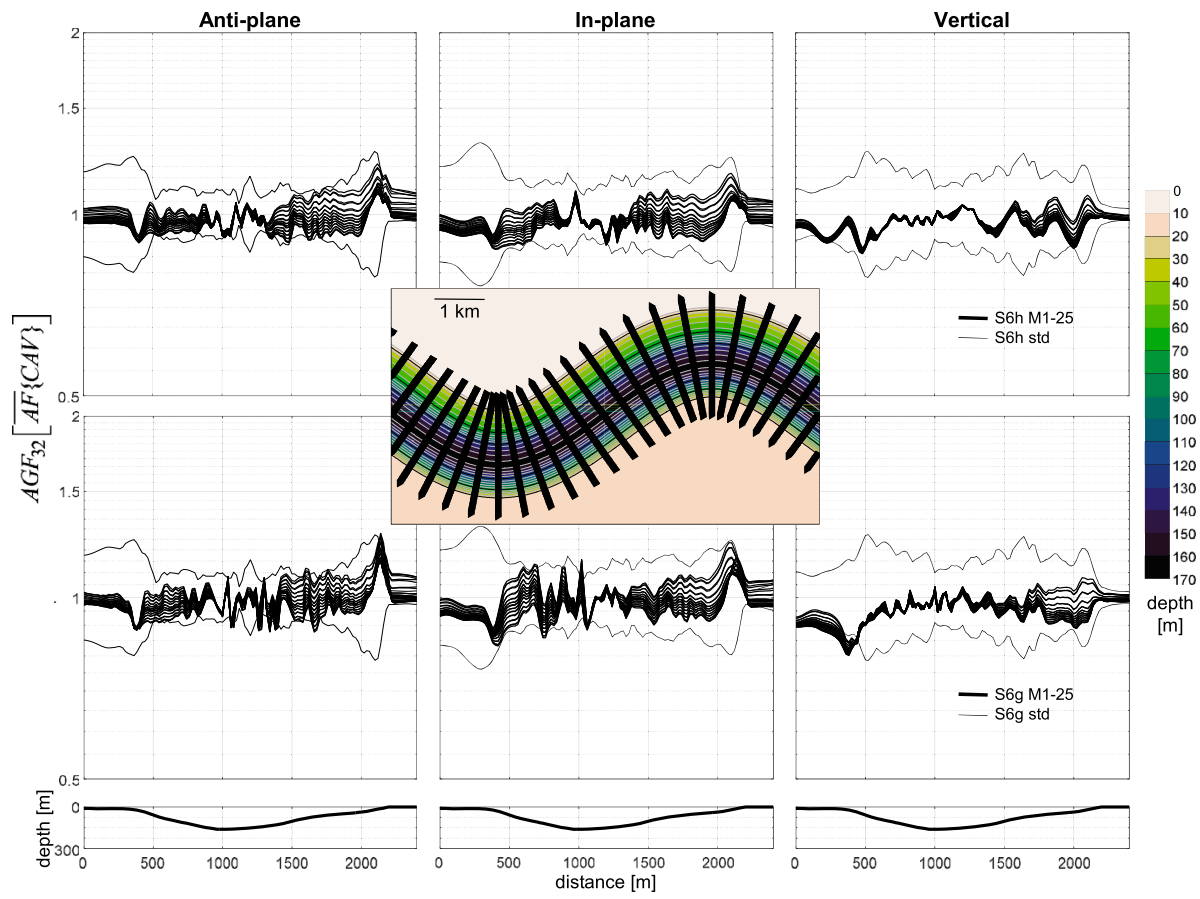

Fig. $203 \mathrm{D} / 2 \mathrm{D}$ aggravation factors for $\overline{A F}\{C A V\}$ for 25 profiles in the $3 \mathrm{D}$ model of the meander-like extension of 2D models S6h and S6g. The standard deviation represents the variability of the input motion

of obliquely incident $\mathrm{S}$ waves at least to account for the already existing S-to-P conversions for either obliquely incident waves or sloping sediment-bedrock interfaces.

For the considered cases (three sites), the 3D/2D aggravation factors are smaller than the corresponding 2D/1D values. They are the most pronounced mainly in the Grenoble site (Site 2) because of the Y shape which cannot be approximated by a 2D profile (profile P4). However, even for such a complex 3D site, the classical, vertically impinging plane wave assumption, is found to provide rather robust and reliable estimates of amplification factors. The plane-wave excitations should not, however, replace a DC point source (or extended sources) if such sources are identified to represent a possible or likely excitation for a given 3D site.

The main partial conclusion is that 1D estimates of EGM characteristics are not sufficient at any of the investigated sites.

This series of computations also led to several semi-quantitative/semi-qualitative findings concerning the sensitivity of aggravation factors to several structural parameters, and to identify the key impact of some of them.

We identified the following key structural parameters:

- As expected the aggravation factor is found to increase with the shape ratio (maximum thickness over valley width). Nevertheless, even relatively shallow valleys (shape ratios as low as 0.05) can lead to significant aggravation factors in case of relatively wide, shallow sloping edge (Site 1, Euroseistest, see also Chaljub et al. 2015; Maufroy et al. 
(a)

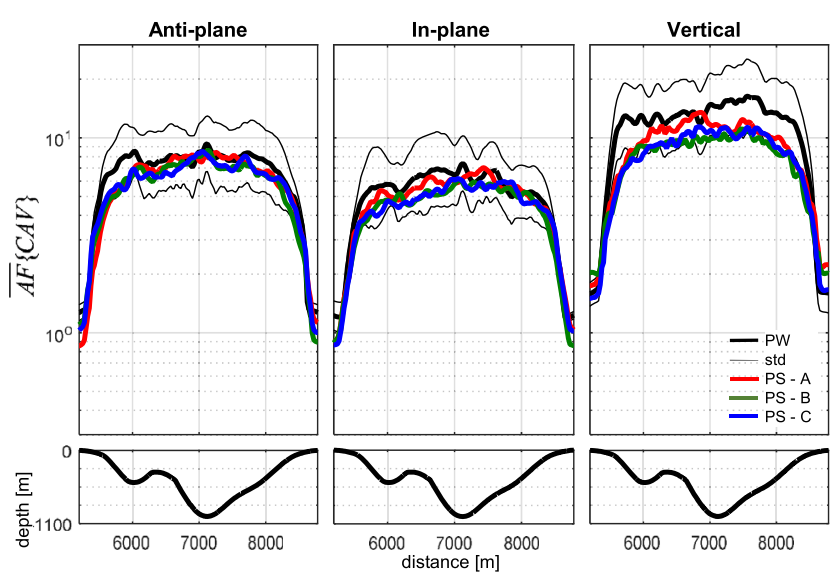

(b)

P1

P2

P3

P4

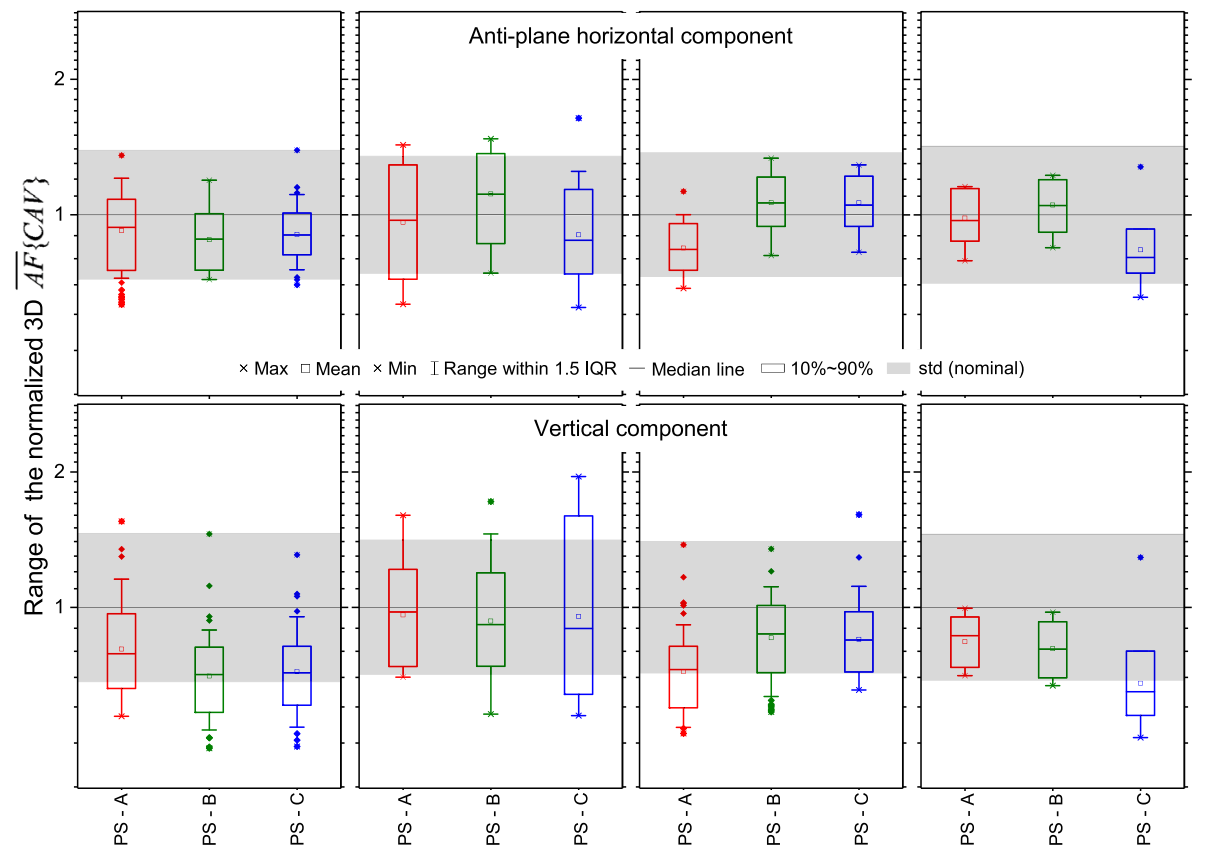

Fig. 21 a Comparison of the amplification factors for $C A V$ for $3 \mathrm{DC}$ point sources $\mathrm{A}, \mathrm{B}$ and $\mathrm{C}$ (PS-A, PS-B and PS - C), and plane wave excitation (PW) for profile P1 at Site 2 (Grenoble valley). b The range of amplification factor for $C A V$ corresponding to the DC point sources $\mathrm{A}, \mathrm{B}$ and $\mathrm{C}$ normalized by the amplification factor corresponding to the plane-wave excitation for the four profiles at Site 2 (Grenoble valley). The standard deviation represents the variability of the input motion

2015 , 2016, 2017). It is thus important to estimate not only the overall shape ratio, but also the overall geometry of the sediment-bedrock interface, in particular the sloping angles of the sediment-bedrock interface on the valley edges; 
- The impedance contrast at the sediment-bedrock interface impacts not only the amplification factor, as expected, but also the aggravation factor: for a given geometry, the larger the impedance contrast, the larger the aggravation factor. This is interpreted as related to the more efficient generation and trapping of surface waves in $2 \mathrm{D}$ and $3 \mathrm{D}$ models.

- The attenuation in sediments similarly impacts both the amplification and aggravation factors: larger attenuation results in smaller amplification and aggravation factors, especially for the vertical component.

- Finally, it is found that, because of these geometrical effects, the amplification factors may largely exceed the values that are usually considered in GMPEs between soft soils and rock sites: this should be kept in mind when dealing with the design of critical, nuclear-like facilities.

Acknowledgements This work was supported in part by project SIGMA (EDF, AREVA, CEA and ENEL) and also by the Slovak Research and Development Agency under the contract APVV-15-0560 (Project IDEFFECTS). Part of the calculations were performed in the Computing Centre of the Slovak Academy of Sciences using the supercomputing infrastructure acquired in project ITMS 26230120002 and 26210120002 (Slovak infrastructure for high-performance computing) supported by the Research and Development Operational Programme funded by the ERDF.

Open Access This article is distributed under the terms of the Creative Commons Attribution 4.0 International License (http://creativecommons.org/licenses/by/4.0/), which permits unrestricted use, distribution, and reproduction in any medium, provided you give appropriate credit to the original author(s) and the source, provide a link to the Creative Commons license, and indicate if changes were made.

\section{References}

Barnaba C, Marello L, Vuan A, Palmieri F, Romanelli M, Priolo E, Braitenberg C (2010) The buried shape of an alpine valley from gravity surveys, seismic and ambient noise analysis. Geophys $\mathrm{J}$ Int 180:715-733

Borcherdt RD (1994) Estimates of site-dependent response spectra for design (methodology and justification). Earthq Spectra 10:617-653

Borcherdt RD (2002) Empirical evidence for acceleration-dependent amplification factors. Bull Seismol Soc Am 92:761-782

Cadet H, Bard P-Y, Duval A-M, Bertrand E (2012) Site effect assessment using KiK-net data: part 2-site amplification prediction equation based on $\mathrm{f} 0$ and Vsz. Bull Earthq Eng 10:451-489

Campbell KW, Bozorgnia Y (2010) A ground motion prediction equation for the horizontal component of cumulative absolute velocity (CAV) based on the PEER-NGA strong motion database. Earthq Spectra 26:635-650

Castellaro S, Mulargia F, Rossi PL (2008) Vs30: proxy for seismic amplification? Seismol Res Lett 79:540-543

Chaljub E, Moczo P, Tsuno S, Bard P-Y, Kristek J, Kaeser M, Stupazzini M, Kristeková M (2010) Quantitative comparison of four numerical predictions of 3D ground motion in the Grenoble Valley, France. Bull Seismol Soc Am 100:1427-1455

Chaljub E, Maufroy E, Moczo P, Kristek J, Hollender F, Bard P-Y, Priolo E, Klin P, de Martin F, Zhang Z, Zhang W, Chen X (2015) 3-D numerical simulations of earthquake ground motion in sedimentary basins: testing accuracy through stringent models. Geophys J Int 201:90-111

Chávez-García FJ (2007) Site effects: from observation and modelling to accounting for them in building codes. In: Pitilakis KD (ed) Earthquake geotechnical engineering. Springer, Berlin, pp 53-72

Chávez-García FJ, Faccioli E (2000) Complex site effects and building codes: making the leap. J Seismol 4:23-40

Day SM, Bielak J, Dreger DS, Graves RW, Larsen S, Olsen KB, Pitarka A (2003) Tests of 3D elastodynamic codes: final report for lifelines project 1A02. Pacific Earthquake Engineering Research Center 
Gelagoti F, Kourkoulis R, Anastasopoulos I, Gazetas G (2012) Nonlinear dimensional analysis of trapezoidal valleys subjected to vertically propagating SV waves. Bull Seismol Soc Am 102:999-1017

Hasal M, Iyisan R (2012) Effect of edge slope on soil amplification at a two dimensional basin model. 15th WCEE, Lisbona, Paper

Kristek J, Moczo P (2014) FDSim3D—the Fortran95 code for numerical simulation of seismic wave propagation in 3D heterogeneous viscoelastic media. www.cambridge.org/moczo. Accessed Feb 2018

Kristek J, Moczo P, Bard P-Y, Hollender F, Stripajová S, Margočová Z, Chaljub E, Durand C (2015) Identification of key site features for site effect evaluation: extensive numerical sensitivity studies of sedimentary basin structures. Deliverable SIGMA-2015-D3-151. Final report for project SIGMA, p 217. (Dissemination: Authors SC, Work Package leaders, Scientific Committee, Archiving)

Kristek J, Moczo P, Bard P-Y, Hollender F, Stripajová S (2018) Computation of amplification factor of earthquake ground motion for a local sedimentary structure. Bull Earthq Eng (this volume)

Kumar S, Narayan JP (2008) Importance of quantification of local site effects based on wave propagation in seismic microzonation. J Earth Syst Sci 117:731-748

Lacave C, Lemeille F (2006) Seismic hazard and alpine valley response analysis: generic valley configurations. In: 1st European conference on earthquake engineering and seismology (a joint event of the 13th ECEE \& 30th general assembly of the ESC) Geneva, Switzerland, 3-8 September, pp 3-8

Luzi L, Puglia R, Pacor F, Gallipoli M, Bindi D, Mucciarelli M (2011) Proposal for a soil classification based on parameters alternative or complementary to Vs, 30. Bull Earthq Eng 9:1877-1898

Makra K, Raptakis D, Chávez-García FJ, Pitilakis K (2001) Site effects and design provisions: the case of Euroseistest. PAGEOPH 158:2349-2367

Makra K, Chávez-García FJ, Raptakis D, Pitilakis K (2005) Parametric analysis of the seismic response of a 2D sedimentary valley: implications for code implementations of complex site effects. Soil Dyn Earthq Eng 25:303-315

Maufroy E, Chaljub E, Hollender F, Kristek J, Moczo P, Klin P, Priolo E, Iwaki A, Iwata T, Etienne V, De Martin F, Theodoulidis NP, Manakou M, Guyonnet-Benaize C, Pitilakis K, Bard PY (2015) Earthquake ground motion in the Mygdonian Basin, Greece: the E2VP verification and validation of 3D numerical simulation up to $4 \mathrm{~Hz}$. Bull Seismol Soc Am 105:1398-1418

Maufroy E, Chaljub E, Hollender F, Bard PY, Kristek J, Moczo P, De Martin F, Theodoulidis N, Manakou M, Guyonnet-Benaize C, Hollard N, Pitilakis K (2016) 3D numerical simulation and ground motion prediction: verification, validation and beyond lessons from the E2VP project. Soil Dyn Earthq Eng 91:53-71

Maufroy E, Chaljub E, Theodoulidis NP, Roumelioti Z, Hollender F, Bard PY, de Martin F, GuyonnetBenaize C, Margerin L (2017) Source-related variability of site response in the Mygdonian Basin (Greece) from accelerometric recordings and 3D numerical simulations. Bull Seismol Soc Am 107:787-808

Moczo P, Irikura K (1999) The Northridge and Kobe simultaneous simulation experiments. In: Irikura K, Kudo K, Okada H, Sasatani T (eds) The effects of surface geology on seismic motion, vol 3. Balkema, Rotterdam, pp 1525-1526

Moczo P, Labák P, Kristek J, Hron F (1996) Amplification and differential motion due to an antiplane 2D resonance in the sediment valleys embedded in a layer over the half-space. Bull Seismol Soc Am $86: 1434-1446$

Moczo P, Kristek J, Gális M (2014) The finite-difference modelling of earthquake motions: waves and ruptures. Cambridge University Press, Cambridge

Narayan J, Richharia AA (2008) Effects of strong lateral discontinuity on ground motion characteristics and aggravation factor. J Seismol 12:557-573

Niccoli M (2014) Geophysical tutorial. How to evaluate and compare color maps. Lead Edge 33:910-912

Paolucci R, Morstabilini L (2006) Non-dimensional site amplification functions for basin edge effects on seismic ground motion. In: Third international symposium on the effects of surface geology on seismic motion. 30. Grenoble, France, August 30-September 1, pp 823-831

Paolucci R, Smerzini C (2018) Empirical evaluation of peak ground velocity and displacement as a function of elastic spectral ordinates for design. Earthq Eng Struct Dyn 47:245-255

Pitilakis K, Riga E, Anastasiadis A (2012) Design spectra and amplification factors for Eurocode 8. Bull Earthq Eng 10:1-24

Pitilakis K, Riga E, Anastasiadis A (2013) New code site classification, amplification factors and normalized response spectra based on a worldwide ground-motion database. Bull Earthq Eng 11:925-966

Riga E, Makra K, Pitilakis K (2016) Aggravation factors for seismic response of sedimentary basins: a codeoriented parametric study. Soil Dyn Earthq Eng 91:116-132

Vessia G, Russo S (2013) Relevant features of the valley seismic response: the case study of Tuscan Northern Apennine sector. Bull Earthq Eng 11:1633-1660 